\title{
Restoration of Kv7 Channel-Mediated Inhibition Reduces Cued-Reinstatement of Cocaine Seeking
}

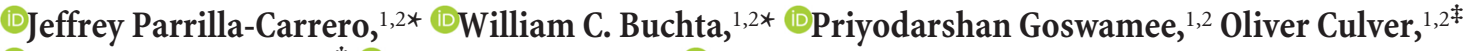 \\ (10Greer McKendrick, ${ }^{1,2}{ }^{\ddagger}$ - Benjamin Harlan, ${ }^{1,2}{ }^{-}$Aubin Moutal, ${ }^{3}$ Rachel Penrod, ${ }^{1,2}$ Abigail Lauer, ${ }^{4}$ \\ Viswanathan Ramakrishnan, ${ }^{4}$-Rajesh Khanna, ${ }^{3}$-Peter Kalivas, ${ }^{1,2}$ and ${ }^{\circ}$ Arthur C. Riegel ${ }^{1,2}$ \\ ${ }^{1}$ Department of Neuroscience, ${ }^{2}$ Neurobiology of Addiction Research Center, Medical University of South Carolina, Charleston, South Carolina 29425, \\ ${ }^{3}$ Department of Pharmacology, University of Arizona, Tucson, Arizona 85724, and ${ }^{4}$ Department of Public Health Sciences., Medical University of South \\ Carolina, Charleston, SC 29425
}

Cocaine addicts display increased sensitivity to drug-associated cues, due in part to changes in the prelimbic prefrontal cortex (PL-PFC). The cellular mechanisms underlying cue-induced reinstatement of cocaine seeking remain unknown. Reinforcement learning for addictive drugs may produce persistent maladaptations in intrinsic excitability within sparse subsets of PFC pyramidal neurons. Using a model of relapse in male rats, we sampled $>600$ neurons to examine spike frequency adaptation (SFA) and afterhyperpolarizations (AHPs), two systems that attenuate low-frequency inputs to regulate neuronal synchronization. We observed that training to self-administer cocaine or nondrug (sucrose) reinforcers decreased SFA and AHPs in a subpopulation of PL-PFC neurons. Only with cocaine did the resulting hyperexcitability persist through extinction training and increase during reinstatement. In neurons with intact SFA, dopamine enhanced excitability by inhibiting Kv7 potassium channels that mediate SFA. However, dopamine effects were occluded in neurons from cocaineexperienced rats, where SFA and AHPs were reduced. Pharmacological stabilization of Kv7 channels with retigabine restored SFA and Kv7 channel function in neuroadapted cells. When microinjected bilaterally into the PL-PFC 10 min before reinstatement testing, retigabine reduced cue-induced reinstatement of cocaine seeking. Last, using cFos-GFP transgenic rats, we found that the loss of SFA correlated with the expression of cFos-GFP following both extinction and re-exposure to drug-associated cues. Together, these data suggest that cocaine self-administration desensitizes inhibitory Kv7 channels in a subpopulation of PL-PFC neurons. This subpopulation of neurons may represent a persistent neural ensemble responsible for driving drug seeking in response to cues.

Key words: afterhyperpolarization; cocaine; dopamine; Kv7 ion channels; prefrontal cortex; spike-frequency adaptation

Significance Statement

Long after the cessation of drug use, cues associated with cocaine still elicit drug-seeking behavior, in part by activation of the prelimbic prefrontal cortex (PL-PFC). The underlying cellular mechanisms governing these activated neurons remain unclear. Using a rat model of relapse to cocaine seeking, we identified a population of PL-PFC neurons that become hyperexcitable following chronic cocaine selfadministration. These neurons show persistent loss of spike frequency adaptation, reduced afterhyperpolarizations, decreased sensitivity to dopamine, and reduced Kv7 channel-mediated inhibition. Stabilization of Kv7 channel function with retigabine normalized neuronal excitability, restored Kv7 channel currents, and reduced drug-seeking behavior when administered into the PL-PFC before reinstatement. These data highlight a persistent adaptation in a subset of PL-PFC neurons that may contribute to relapse vulnerability.

\section{Introduction}

The prelimbic prefrontal cortex (PL-PFC) plays an important role in relapse to cocaine seeking. This brain region filters input from sensory and limbic areas and is critical for initiating appetitive behaviors via its projections to the basal ganglia (Graybiel, 2008). Chronic exposure to drugs of abuse causes changes in the PL-PFC and other learning- and memory-related brain struc-

\footnotetext{
Received Sept. 24, 2017; revised March 27, 2018; accepted March 29, 2018.

Author contributions: J.P.-C., W.C.B., P.G., O.C., A.M., R.K.,P.K., and A.C.R. designed research;J.P.-C., W.C.B.,P.G., O.C., G.M., B.H., A.M., R.P., R.K., and A.C.R. performed research; J.P.-C., W.C.B., P.G., O.C., G.M., B.H., A.M., R.P., A.L., V.R., R.K., P.K., and A.C.R. analyzed data; W.C.B., O.C., A.M., R.K., P.K., and A.C.R. wrote the paper.

This research was supported by National Institute on Drug Abuse Grants F31-DA-036989 (W.C.B.), T32-DA007288 [J.P.-C, W.C.B. (Program Director: Jakie McGinty)], R01-DA-027664 (Principal Investigator: Christoper Cowan), R01-NS-098772 (Principal Investigator: R.K.), R01-DA-042852 (Principal Investigator: R.K.), P50-DA015369 (Principal Investigator: A.C.R.; Program Director: P.K.), and R01-DA-033342A (A.C.R.).
}

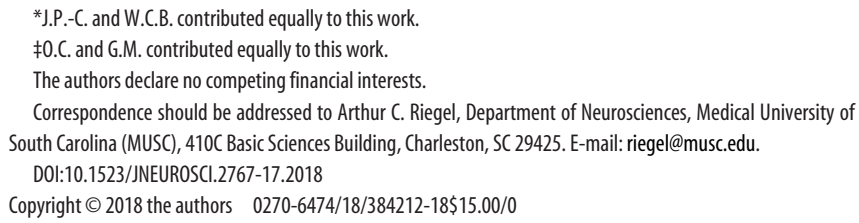


tures that contribute to relapse (Hyman et al., 2006; Williams and Adinoff, 2008). Specifically, after extinction (Ext) from chronic cocaine self-administration (cocaine-SA), activated glutamatergic efferents from the PL-PFC innervating the nucleus accumbens drive cue-induced reinstatement of drug seeking (Kalivas and McFarland, 2003; See, 2009; Stefanik et al., 2016).

Behaviorally relevant cues activate only a small portion of neurons within a brain region (Cruz et al., 2013, 2015). Across many brain regions, these sparse ensembles of activated neurons contribute to the processing of sensory cues and are thought to store the memory trace for such learned associations (Matsumoto and Hikosaka, 2009; Euston et al., 2012; Pinto and Dan, 2015). These neuronal ensembles of activated neurons can be identified using immediate early gene indicators like cFos, whose expression increases following strong neural activation (Morgan et al., 1987; Morgan and Curran, 1988; Herrera and Robertson, 1996). For example, following cue-induced reinstatement, PLPFC neurons that project to the accumbens core show robust cFos activation, while cells that project to the accumbens shell do not. This PL-PFC-accumbens core pathway is recruited in a dopamine-dependent manner to drive drug seeking in response to cues (McGlinchey et al., 2016). Dopamine signaling can induce cFos expression (Zhang et al., 2006) and promote the formation and maintenance of activity within cellular neural ensembles (O’Donnell, 2003; Puig and Miller, 2012; Miyawaki et al., 2014). However, the cellular adaptations that occur within these activated ensembles in the PL-PFC remain unclear.

At the cellular level, spike frequency adaptation (SFA) and afterhyperpolarizations (AHPs) are two principle forces regulating neuronal synchronization (Crook et al., 1998; Prescott and Sejnowski, 2008; Prescott et al., 2008). SFA decreases responses to nonpreferred stimuli (Benda et al., 2005; Peron and Gabbiani, 2009). However, SFA is typically dynamic and reduced by many neuromodulators. For example, we recently showed that dopamine release from ventral tegmental area (VTA) terminals in the PL-PFC can reduce SFA (Buchta et al., 2017). In other brain regions, reduced SFA in ensembles of cells can enhance memory storage and behavioral responses to cues encoded by the ensemble (Yiu et al., 2014). Across multiple brain regions and behavioral paradigms, reduced SFA is associated with learning (Moyer et al., 1996; McKay et al., 2009; Sehgal et al., 2014). Relative to nondrug reinforcers such as sucrose, drugs of abuse produce robust, long-lasting neural changes that result in stronger, more persistent behavioral responding for drugs (Ciccocioppo et al., 2004; Tunstall and Kearns, 2016). Thus, reinforcement learning for drugs may produce persistent adaptations in SFA that contribute to enduring cue-reward associations and the subsequent ability of cues to elicit drug-seeking behavior. However, whether SFA is disrupted in the PL-PFC following chronic cocaine selfadministration and how this contributes to relapse to drug seeking have not been previously examined.

Here, we used ex vivo electrophysiology to examine SFA following cocaine self-administration training, extinction, and reinstatement. We assessed whether previous cocaine selfadministration experience modified the responses of activated neurons to dopamine. We also examined the function of the Kv7 potassium channels contributing to SFA and assessed whether dysfunction of these channels contributed to drug-seeking behavior in response to cues. Last, we used cFos-green fluorescent protein (GFP) transgenic rats to identify and record from cFos$\mathrm{GFP}^{+}$neurons and examine whether SFA changes were specific to $\mathrm{GFP}^{+}$neurons. Our results identify a subset of cFos-GFP ${ }^{+}$ PL-PFC neurons that show a persistent loss of SFA and Kv7 chan- nel inhibition following chronic cocaine self-administration. We further show that pharmacological stabilization of Kv7 channels with retigabine restores SFA and Kv7 channel inhibition, and reduces cue-induced reinstatement. These cells may represent an enduring neural ensemble that maintains drug-cue associations and drives drug seeking in response to cues.

\section{Materials and Methods}

\section{Animals}

We used adult (i.e., more than postnatal day 65) male Sprague Dawley rats (Charles River Laboratories) and transgenic cFos-GFP Long-Evans rats (bred in-house; breeding pair provided by Dr. Bruce Hope, NIDAIRP, NIH), each weighing between 250 and $300 \mathrm{~g}$ at the beginning of experiments. Rats were individually housed in a temperature- and humidity-controlled environment under a reversed $12 \mathrm{~h}$ light/dark cycle (lights on at 6:00 P.M.). Rats were acclimated for a minimum of 1 week before surgeries and had access to food and water ad libitum. All procedures, killings, and behavioral experiments were performed during the dark cycle, and in accordance with guidelines obtained from the National Institutes of Health for the care of laboratory animals and by the Medical University of South Carolina Institutional Animal Care and Use Committee.

\section{Surgery}

Surgical procedures were performed on rats to implant catheters for receiving intravenous cocaine or saline infusions, or intracranial cannulae for the injection of pharmacological compounds directly to the prelimbic cortex. Rats were anesthetized using a ketamine $\mathrm{HCl}$ /xylazine mixture $(0.57 / 0.87 \mathrm{mg} / \mathrm{kg}$, respectively, i.p.) followed by ketorolac $(2.0$ $\mathrm{mg} / \mathrm{kg}$, i.p.) and Cefazolin (40 mg, i.p., or $10 \mathrm{mg} / 0.1 \mathrm{ml}$, i.v.). Subsequently, intrajugular catheters were implanted as described previously (Spencer et al., 2017). Catheter patency was maintained by daily flushing with cefazolin ( $1 \mathrm{~g} / 5 \mathrm{ml}$ during surgery and $1 \mathrm{~g} / 10 \mathrm{ml}$ daily for 1 week) and then with heparin for the remainder of the behavioral paradigms. Some rats received bilateral intracranial microinjections of either retigabine or vehicle [dimethylsulfoxide (DMSO)] via cannulae (double 28 ga barrel; 1.2-1.5 mm C-C; Plastics One) that were stereotactically implanted into the brain and reached $1 \mathrm{~mm}$ above PL-PFC using the following coordinates relative to bregma (in $\mathrm{mm}$; anteroposterior, +3.0-3.5; dorsoventral, -3.0 ; mediolateral, \pm 0.75 ).

\section{Behavioral procedures}

The rationale underlying the self-administration, extinction, and cued reinstatement testing has been described in detail previously (Steketee and Kalivas, 2011; Bossert et al., 2013). The general timeline outlining the different behavioral phases is shown in Figure 1A. For Experiments 1, 2, 4 , and 5 , rats were trained to self-administer cocaine (i.e., the cocaine-SA group) on a fixed ratio 1 (FR1) schedule of reinforcement ( $2 \mathrm{~h} /$ session). Intravenous injection of cocaine $(\sim 0.2 \mathrm{mg} / \mathrm{kg} /$ infusion $)$ was delivered contingent to pressing one (active) of two levers in response to a compound light $(5 \mathrm{~s})$ and tone $(4 \mathrm{kHz}, 78 \mathrm{~dB}, 5 \mathrm{~s})$ cue that was followed by a $20 \mathrm{~s}$ time-out period. Each training session lasted $2 \mathrm{~h}$, after which animals were returned to their home cages. A parallel set of time-matched control rats were "yoked" to the cocaine-SA group and received either saline (saline-yoked group) or noncontingent infusions of cocaine (cocaineyoked group) every time the paired cocaine-SA rat pressed the active lever during the self-administration phase (Fig. $1 A$ ).

Experiment 1. Following the maintenance of stable self-administration behavior for 14 consecutive days ( $>10$ infusions/session), the salineyoked, cocaine-yoked, and cocaine-SA rats were killed $24 \mathrm{~h}$ after the last training session to harvest brain tissue for electrophysiological recordings (see Fig. 3).

Experiment 2. Twenty-four hours after the last cocaine self-administration (or yoked) training session, animals entered into extinction training to extinguish lever-pressing behavior (see Fig. 4). During the extinction period (14-19 d), the pressing of the active lever yielded neither cocaine nor the light/tone cue. Once the self-administration behavior was stably extinguished in cocaine-SA rats ( $<25$ active lever presses for 3 consecutive days), saline-yoked and cocaine-SA rats were killed $15 \mathrm{~min}$ after 


\section{A behavioral training fextinction fcue phases: $14 d$

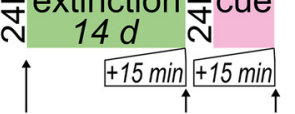 e-phys time points: $15 d$}

\section{group treatment \\ cocaine-SA self-admin. cocaine \\ saline-Yoked yoked saline \\ cocaine-Yoked yoked cocaine \\ sucr-SA self-admin. sucrose}

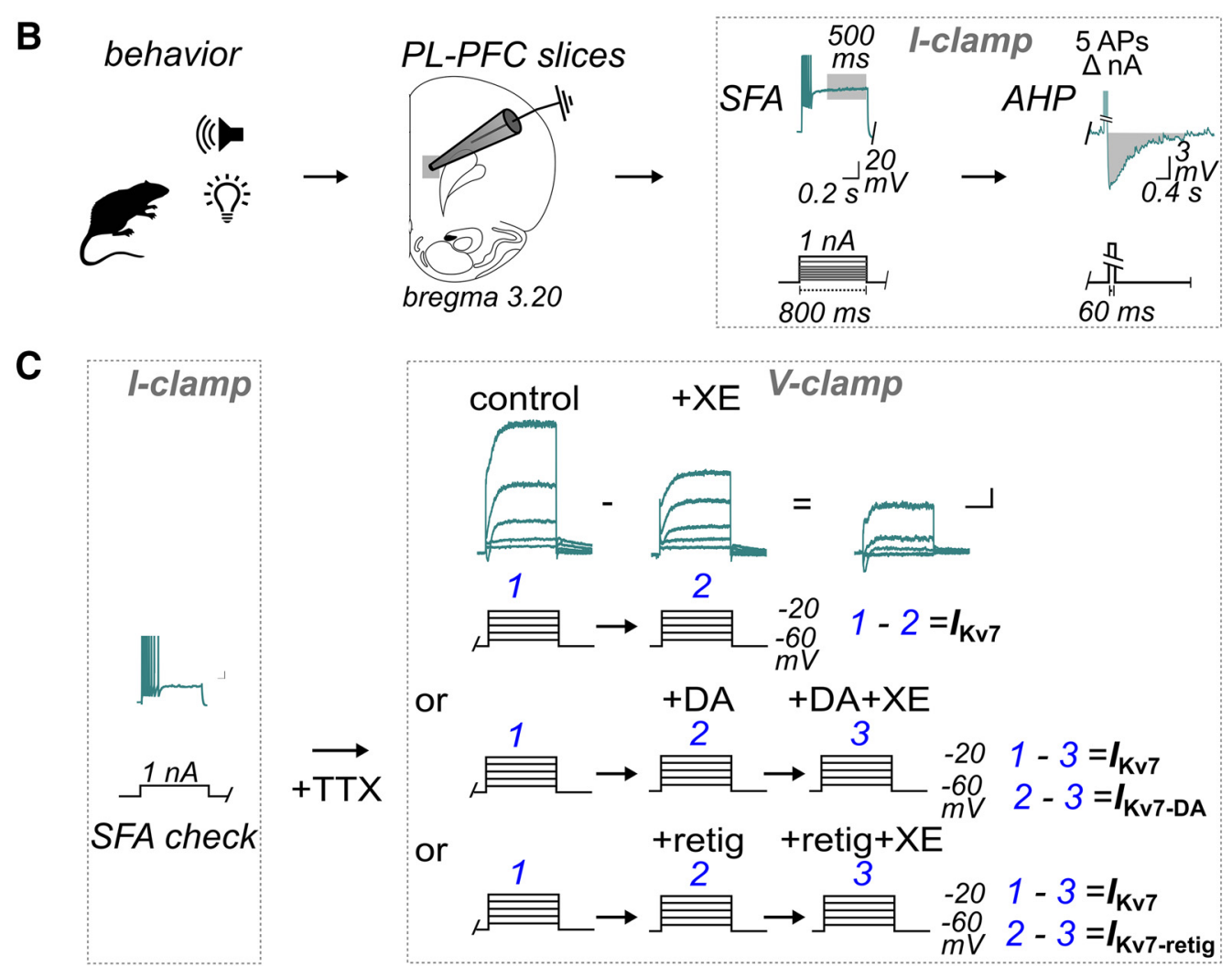

Figure 1. Experimental outline for behavioral training and physiological measurements. $\boldsymbol{A}$, Timeline shows the different behavioral phases, time points of electrophysiological measurements (e-phys), and the color-coded treatment groups. $\boldsymbol{B}$, After behavioral end points, brain slices containing PL-PFC were made for current-clamp measurements of SFA (measured during the final 500 ms of the step) and AHPs generated in response to five APs (expressed as the area under the curve). $\boldsymbol{C}$, In some experiments, after measuring firing to check for SFA with a $1 \mathrm{nA}$ step, the $I_{\text {Kv7 }}$ was determined in voltage clamp. Currents were evoked with voltage steps ( -60 to $-20 \mathrm{mV} ; 800 \mathrm{~ms}$; in $200 \mathrm{~nm}$ TTX). Currents generated after 8 min of incubation of the Kv7 channel antagonist, XE-991 (XE; $20 \mu \mathrm{m}, 8 \mathrm{~min}$ ) was subtracted from control (predrug) currents. To determine the effect of dopamine (DA; $10 \mu \mathrm{m}$ ) or the Kv7 channel stabilizer retigabine (retig; $20 \mu \mathrm{m}$ ) on $I_{\mathrm{Kv} 7}$, the currents

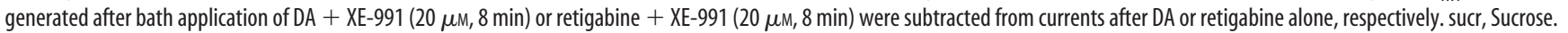

completion of their last extinction session to harvest brain tissue for electrophysiological recordings.

Experiment 3. After the last cocaine self-administration session (see Fig. 5), six cocaine-SA rats were returned and remained in their home cage for the remainder of a $14 \mathrm{~d}$ withdrawal period (see Fig. $5 \mathrm{~A}$ ). Rats were killed on the last day of withdrawal for electrophysiological recordings. Another group of five unhandled and behaviorally naive rats were also killed for brain slices (see Fig. 5B). A third group of 12 rats was trained to self-administration sucrose (sucrose-SA; see Fig. 5C) using a procedure similar to those used in previously published studies (McGlinchey et al., 2016), where rats were handled daily for at least 1 week before sucrose self-administration training. Rats were trained to self-administer sucrose on an FR1 schedule of reinforcement $(2 \mathrm{~h} / \mathrm{ses}-$ sion) in operant chambers within sound-attenuating boxes, controlled by Med-PC IV software (Med Associates). Sucrose pellets ( $45 \mathrm{mg}$, Test Diet) were delivered contingent to pressing one (active) of two levers in response to a compound light $(5 \mathrm{~s})$ and tone cue $(4 \mathrm{kHz}, 78 \mathrm{~dB}, 5 \mathrm{~s})$ followed by a $20 \mathrm{~s}$ time-out period, where additional presses had no programmed consequences. Presses on the inactive lever were recorded but had no programmed consequences. After 10-14 d of criterion sucrose-SA performance ( $\geq 30$ pellets/session), one group of six rats was killed $24 \mathrm{~h}$ after the last training session to harvest brain tissue for electrophysiological recordings. The remaining six rats underwent extinc- tion training, where responding on either lever had no consequence. Rats received extinction training for a minimum of $10 \mathrm{~d}$ and until they met the criteria of $<25$ active lever presses for $\geq 3$ consecutive days. Rats were killed $15 \mathrm{~min}$ after the last extinction session to harvest brain tissue for electrophysiological recordings.

Experiment 4. Once cocaine self-administration was completed and behavioral responding was stably extinguished $(<25$ active lever presses for 3 consecutive days), saline-yoked and cocaine-SA rats returned to the home cage for $24 \mathrm{~h}$ (see Fig. 6). The next day, they were tested for cueinduced reinstatement of lever pressing (Epstein et al., 2006). During the $2 \mathrm{~h}$ test, rats were re-exposed to the cocaine-paired cues (but, not cocaine) with a $20 \mathrm{~s}$ time-out period after each press of the active lever. Rats were killed immediately at the end of the $2 \mathrm{~h}$ test for electrophysiological recordings. In a separate set of cocaine-SA rats ( $n=27$ rats), retigabine $(0.0015 / 0.015 / 0.15 \mathrm{nmol} / 0.5 \mu \mathrm{l}$ prepared in saline with $0.1 \%$ DMSO) or vehicle $(0.1 \%$ DMSO in $0.5 \mu \mathrm{l}$ of saline) was microinjected into the PL-PFC $10 \mathrm{~min}$ before $2 \mathrm{~h}$ cued-induced reinstatement sessions. A randomized counterbalanced design with two to three cue reinstatement tests was used, with at least $2 \mathrm{~d}$ of extinction ( $\leq 25$ active lever presses) between tests (Smith et al., 2014). Following the completion of reinstatement testing, locomotor testing was conducted in novel open-field chambers (AccuScan Instruments). PL-PFC infusions (identical to those described above) of either retigabine or vehicle were made $10 \mathrm{~min}$ before 
placement in the open-field chambers. The total distance traveled in the following $2 \mathrm{~h}$ was quantified using Versamax software. Data were included for analysis only if the histology identifying the center of injection sites confirmed PL-PFC cannulas placements, which ranged from $\sim 3.2-$ $4.2 \mathrm{~mm}$ anteroposterior.

Experiment 5. Transgenic cFos-GFP rats were trained to self-administer cocaine (i.e., the cocaine-SA group) using the same procedure as described above (see Fig. 7). A parallel set of time-matched control rats were "yoked" to the cocaine-SA group, but received saline (saline-yoked group) every time the paired cocaine-SA rat pressed the active lever during the self-administration phase. Following the same procedure as in Experiment 1, four saline-yoked and five cocaine-SA rats were killed immediately after the last 90 min extinction session to harvest brain tissue for electrophysiological recordings. The remaining four salineyoked and 11 cocaine-SA rats underwent extinction training as described in Experiment 4 and then tested for cued reinstatement of lever pressing as described in Experiment 4, except that the session lasted 90 min. Rats were killed immediately at the end of the 90 min cue test for electrophysiological recordings.

\section{Pharmacological compounds}

Cocaine hydrochloride was obtained through the Drug Supply Program of the National Institute on Drug Abuse. DMSO and D-glucose were purchased from Sigma-Aldrich. All salts used in the preparation of physiological buffers were purchased from Fisher Chemicals. Dopamine, XE991, kynurenic acid, and MK-801 maleate (dizocilpine) were purchased from Abcam. Retigabine was purchased from Axon Medchem.

\section{PFC slice preparation}

Rats were killed by rapid decapitation, the brain was removed, and a tissue block containing the PL-PFC was placed in ice-cold and oxygenated artificial CSF (aCSF), as follows (in mM[SCAP]): $126 \mathrm{NaCl}, 2.5 \mathrm{KCl}$, $1.2 \mathrm{MgCl}_{2}, 1.4 \mathrm{NaH}_{2} \mathrm{PO}_{4}, 25 \mathrm{NaHCO}_{3}, 11$ D-glucose, 0.4 ascorbate supplemented with MK-801 maleate $(10 \mu \mathrm{M})$ and kynurenic acid (2.6 mM; Riegel and Williams, 2008; Williams et al., 2014). Thick sections ( 200 $\mu \mathrm{M}$ ) containing the PL-PFC region (Fig. $1 B$ ) were prepared using a vibrating microtome (Leica) and maintained in a vial containing MK-801 maleate $(10 \mu \mathrm{M})$ dissolved in oxygenated aCSF in a $32^{\circ} \mathrm{C}$ water bath until recording. During recording, sections were perfused at a flow-rate of 2 $\mathrm{ml} / \mathrm{min}$ with oxygenated aCSF at $33^{\circ} \mathrm{C}$. The prelimbic layer $\mathrm{V} / \mathrm{VI}$ was identified initially using a $5 \times$ objective, and later was magnified for patching with a $63 \times(0.9$ numerical aperture $)$ water-immersion lens fitted to an upright microscope (model BX 51WI, Olympus) equipped with gradient contrast infrared optics. GFP was visualized by fluorescence using a purpose-built LED system composed of parts from Thorlabs.

\section{Electrophysiological procedures}

Whole-cell recordings were performed using multiclamp 700B amplifiers (Molecular Devices). Neurons were voltage clamped at $-70 \mathrm{mV}$ using 1.5-2.5 $\mathrm{M} \Omega$ glass microelectrodes filled with the following internal solution (in mM[sCAP]): $115 \mathrm{~K}$-methylsulfate, $20 \mathrm{NaCl}, 1.5 \mathrm{MgCl}_{2}, 2.5$ HEPES, 2 ATP, 0.3 GTP, and 0.1 EGTA, pH 7.3 and 265-270 mOsm. Series resistance $(<10 \mathrm{M} \Omega$ ) was compensated at $80 \%$, and only cells with $<15 \%$ series resistance change after drug application were included in the analysis. Recordings were collected on-line using AxoGraph X (AxoGraph Scientific) and digitized at 2-5 kHz. Layer V pyramidal cells were identified by location, morphology, and electrophysiological criteria including their characteristic hyperpolarized resting membrane potential and low input resistance (Gulledge and Jaffe, 1998; Ceci et al., 1999; Rosenkranz and Grace, 2002; Song et al., 2015). Passive membrane properties in these cells were consistent with published results (Gulledge and Jaffe, 1998; Ceci et al., 1999; Rosenkranz and Grace, 2002; Song et al., 2015) and did not vary among any of the treatment groups at any phase of behavioral training (average all groups across treatments: resting membrane potential: $-67.2 \pm 0.7 \mathrm{mV}, F_{(11,610)}=1.084, p=0.3715$; input resistance: $58 \pm 2.0 \mathrm{M} \Omega, F_{(11,747)}=1.306, p=0.2160$; membrane capacitance: $\left.30.8 \pm 1.0 \mathrm{pF} / \mathrm{cm}^{2}, F_{(11,537)}=1.529, p=0.1172\right)$. Brain slices prepared at the culmination of the behavioral assay (Fig. 1B) were used for current-clamp (I-clamp) recordings in Experiment 3 (see Figs. 5, 7).
Experiments 1, 2, and 4 contain both $I$-clamp and voltage-clamp ( $V$ clamp) recordings (see Figs. 3, 4, 6).

For I-clamp experiments, the bridge was balanced routinely. Using published criteria, input-output (I-O) curves of action potential (AP) firing were generated by injecting a series of eight $0.8 \mathrm{~s}$ current steps, $1 \mathrm{~s}$ interval $(100,200,300,400,500,600,800$, and $1000 \mathrm{pA})$ and counting the numbers of APs evoked during the last $500 \mathrm{~ms}$ in each step epoch (Fig. $1 B$; Madison and Nicoll, 1984; Storm, 1990; Faber et al., 2001; Buchta et al., 2017). All firing traces shown represent the response to $1000 \mathrm{pA}$ current injections. SFA or spike frequency accommodation is defined as the slowing of neuronal firing during a depolarizing current step (Madison and Nicoll, 1982; Lancaster and Nicoll, 1987; Aiken et al., 1995; Shah et al., 2006). Based on published studies, we identified SFA-positive $\left(\mathrm{SFA}^{+}\right)$neurons as those showing five or fewer spikes during the final $500 \mathrm{~ms}$ of the $1 \mathrm{nA}$ current injection (Madison and Nicoll, 1982; Lancaster and Nicoll, 1987; Aiken et al., 1995; Shah et al., 2006). AHPs were measured following calibration of a $60 \mathrm{~ms}$ current injection step to yield a burst of five APs from a holding potential of $-70 \mathrm{mV}$ (Fig. $1 \mathrm{~B}$; Coulter et al., 1989; Moyer et al., 2000; Gu et al., 2005). Because there are no clear criteria for the separation of slow and medium AHPs, we calculated total AHPs as the area below baseline following the fifth AP and the return of the membrane potential to baseline values (Coulter et al., 1989; Moyer et al., 2000; Gu et al., 2005).

For voltage-clamp experiments (Fig. 1C), cells were first sorted as spike frequency-adapting $\mathrm{SFA}^{+}$or $\mathrm{SFA}^{-}$by a single $1000 \mathrm{pA} / 800 \mathrm{~ms}$ current injection in I-clamp. After switching to $V$-clamp, $200 \mathrm{~nm}$ tetrodotoxin (TTX) was continuously applied to the bath perfusate. After 5 min, outward currents were generated in response to a series of long ( 800 $\mathrm{ms}$ ) depolarizing steps ( -60 to $-20 \mathrm{mV}, 10 \mathrm{mV}$ increment). Because Kv7 conductance is a component of this net outward current (and not the total current), the outward currents were measured again after perfusion of the Kv7 channel antagonist XE-991 (20 $\mu \mathrm{M}$, for $10 \mathrm{~min}$; Fig. 1C). The long, slow Kv7 channel current $\left(I_{\mathrm{Kv} 7}\right)$ activation kinetics and sensitivity to XE-991 have been characterized in previous reports (Delmas and Brown, 2005; Lawrence et al., 2006; Brown and Passmore, 2009). Consistent with published results, $I_{\mathrm{Kv} 7}$ was voltage dependent, outwardly rectifying, and actively positive to $-50 \mathrm{mV}$ (Delmas and Brown, 2005; Lawrence et al., 2006; Brown and Passmore, 2009). The $I_{\mathrm{Kv} 7}$ was measured by subtracting the outward currents generated in the presence of XE-991 from the baseline (predrug; Fig. 1C; Wang et al., 1998; Huang and Trussell, 2011). When the effects of dopamine or retigabine on Kv7 channel function were measured, cells were first sorted as SFA ${ }^{+/-}$, then voltage clamped and injected with a series of five long ( $1 \mathrm{~s})$ depolarizing steps $(-70$ to $-20 \mathrm{mV}, 10 \mathrm{mV}$ increment $)$ in the presence of $200 \mathrm{~nm}$ TTX (Fig. 1C). The outward current was measured 5 min after perfusion with $10 \mu \mathrm{M}$ dopamine or $20 \mu \mathrm{M}$ retigabine, and again $10 \mathrm{~min}$ after perfusion with dopamine plus $20 \mu \mathrm{M}$ XE-991 or retigabine plus $20 \mu \mathrm{M}$ XE-991 (Fig. $1 C$ ). The amplitude of the Kv7 current before and after dopamine or retigabine treatment was computed by subtracting the final set of currents from the first and second sets of currents, respectively (Fig. 1C). Recovery from dopamine or retigabine was not regularly examined, as full washout can exceed $25 \mathrm{~min}$, a duration of time that negatively impacts the quality of patch-clamp recordings in older animals that have undergone operant training (Yang and Seamans, 1996; Zheng et al., 1999; Henze et al., 2000; Gorelova et al., 2002). The $10 \mu \mathrm{M}$ dopamine concentration for study was selected for its relevance to earlier studies using concentrations of 10-30 $\mu \mathrm{M}$ (Malenka and Nicoll, 1986).

\section{cFos immunohistochemistry}

Immunohistochemical methods for verification of the cFos-GFP rats were adapted from previous studies (Taniguchi et al., 2017). Fluorescence labeling was used to quantify the colocalization of the intrinsic GFP signal (c-fos) and the protein product of the immediate early gene ( $\mathrm{cFos}$ ) between different treatment groups of the self-administration paradigm in layer $\mathrm{V}$ of the PFC. Sections were washed $3 \times 7 \mathrm{~min}$ in PBS, pH 7.4, and incubated for $1 \mathrm{~h}$ in blocking solution (3\% BSA, $0.3 \%$ Triton X-100, $0.2 \%$ Tween, 3\% normal donkey serum in PBS). Sections were then incubated overnight at $4^{\circ} \mathrm{C}$ with anti-Fos goat primary antibody (catalog \#sc-52-G, lot B2513, Santa Cruz Biotechnology) diluted 1:1000 in blocking solution 
and anti-GFP chicken (catalog \#GFP-1020, lot 0316FP11, Aves Labs). Sections were washed in PBS $3 \times 7 \mathrm{~min}$ and incubated for $1.5 \mathrm{~h}$ at room temperature with donkey anti-chicken 488 (catalog \#703-545-155, lot 119192, Jackson ImmunoResearch) 1:200 and donkey anti-goat Cy3 (catalog \#705-165-147, lot 132480, Jackson ImmunoResearch) 1:200. Sections were washed, dehydrated, and mounted using ProLong Gold Antifade Mountant with DAPI (Thermo Fisher Scientific).

c-Fos GFP and Fos colocalization quantification

Ninety minutes after the start of the final day of self-administration of cocaine or yoked-saline or the first day of extinction training, rats were deeply anesthetized with isoflurane, as described previously (Cifani et al., 2012), and transcardially perfused [ $150 \mathrm{ml}$ of saline and $150 \mathrm{ml}$ of $4 \%$ paraformaldehyde (PFA) in PBS]. Whole-brain specimens were postfixed in $4 \%$ PFA for $24 \mathrm{~h}$ and transferred into PBS for $24 \mathrm{~h}$ until immunohistochemistry procedures were conducted to confirm the c-Fos GFP transgene, as described previously (Cifani et al., 2012). The total c-Fos GFP/anti-Fos cell counts, the Pearson's correlation coefficients, and the Mander's overlap coefficients describing the coexpression of antibody staining for Fos and c-Fos GFP were obtained to verify the efficacy of the c-Fos GFP transgene (see Fig. 7). A confocal microscope (Zeiss LSM 510) was used to image PFA fixed brain sections. Fluorescent images of layer $\mathrm{V}$ PFC were taken using both Leica and NIS Elements Software (Nikon). Quantification of the colocalization of the GFP expression (indicative of c-fos) and the fos immunofluorescence was conducted using the Nikon NIS Elements Software on $10 \times$ bilateral images of layer V PFC.

\section{Western blotting}

Samples of the PL-PFC were lysed by sonication in RIPA buffer [ $50 \mathrm{~mm}$ Tris-HCl, pH 7.4, $50 \mathrm{~mm} \mathrm{NaCl}, 2 \mathrm{~mm} \mathrm{MgCl}_{2}, 1 \%$ (v/v) NP40, 0.5\% (mass/vol) sodium deoxycholate, and $0.1 \%$ (mass/vol) SDS], protease (catalog \#B14002, BioTool) and phosphatase inhibitors (catalog \#B15002, BioTool), and BitNuclease (catalog \#B16002, BioTool). After sonication, lysates were clarified by centrifugation $(15,000 \times g, 10 \mathrm{~min}$, $4^{\circ} \mathrm{C}$ ), then protein concentrations were determined using the BCA Protein Assay (catalog \#PI23225, Thermo Fisher Scientific). Approximately $15 \mu \mathrm{g}$ of total proteins were loaded onto an SDS-PAGE gel and then transferred to polyvinylidene difluoride membranes $(0.45 \mu \mathrm{m})$ and blocked at room temperature for $1 \mathrm{~h}$ in TBST (50 mM Tris-HCl, pH 7.4, $150 \mathrm{~mm} \mathrm{NaCl}, 0.1 \%$ Tween 20) and 5\% nonfat dry milk. Primary antibodies used for probing KCNQ2 (catalog \#APC-050, Alomone Labs), KCNQ3 (catalog \#APC-051, Alomone Labs), KCNQ5 (catalog \#APC155, Alomone Labs), and actin (catalog \#A2066, Sigma-Aldrich) were diluted in TBST with 5\% BSA. Immunoblots were revealed by enhanced luminescence (WBKLS0500, Millipore) before exposure to a photographic film. Films were scanned, digitized, and quantified using UnScan-It gel version 6.1 scanning software (Silk Scientific).

\section{Experimental design and statistical analysis}

All data are reported as the mean \pm SEM, and statistical analyses were performed using GraphPad Prism. Electrophysiological data were analyzed using Axograph X. We used a generalized linear mixed-model ANOVA accounting for the clustering of cells within rats, as well as accounting for rats being used more than once to evaluate cell responses before and after drug application. This was achieved using two random effects in the analysis, one for the rats and another for cells within rats. An interaction between current or membrane potential and drug treatment was also included in the model. The between-subject variable was treatment (cocaine-SA, cocaine-yoked, saline-yoked, sucrose-SA), and the repeated measure was current (for action potential firing) or membrane potential (for current amplitude). Using least-squares means from the model, post hoc comparisons of drug treatment groups before and after were made with a Tukey adjustment for data related to Figures $3 D, 4 D$, and $7, F$ and $G$, or a Sidak multiple-comparisons test for all other analysis. Model assumptions were evaluated based on the residuals, and no violations were found. AHP differences expressed as the area under the curve were evaluated using one-way repeated-measures ANOVAs or unpaired $t$ tests. Two-way mixed repeated-measures ANOVAs were used to evaluate the effects of treatment (cocaine, saline, and sucrose), excitability (firing or current amplitude), and time (repeated steps of current or membrane potential). All statistical evaluations of Kv7 channel $I-V$ curves were conducted at data points positive to $-50 \mathrm{mV}$, when channels are open and not inactivated (Lawrence et al., 2006; Huang and Trussell, 2011; Battefeld et al., 2014). Current and action potential responses of control and treated rats were typically compared at the maximal difference ( $1 \mathrm{nA}$ for action potential firing or $-20 \mathrm{mV}$ for membrane currents). For graphical purposes and clarity, data are often presented separately for the cocaine and saline treatment groups. Data represent the mean \pm SEM, with a $\alpha$ set at $p<0.05$.

\section{Results}

This study addressed three interrelated questions. (1) What are the long-lasting alterations in PL-PFC excitability that occur following cocaine self-administration (withdrawal and extinction)? (2) What are the acute alterations in excitability that occur immediately following cue-induced reinstatement of cocaine seeking? (3) Do the observed alterations contribute to the cueinduced reinstatement of cocaine seeking?

To address these questions, we used the self-administration model of relapse to drug seeking (Shaham et al., 2003). Rats were trained to self-administer cocaine $(0.20 \mathrm{mg} / \mathrm{kg} /$ infusion $)$ for $14 \mathrm{~d}$ in operant chambers where drug infusions were paired with light/ tone cues (Fig. $1 A$ ). All rats showed stable cocaine-SA responding (Fig. 2A). Parallel groups of rats received yoked infusions of saline or yoked infusions of cocaine (Fig. $2 A$ ). No differences in the total number of drug or saline infusions were found among the three groups (one-way ANOVA, $F_{(2,70)}=1.819, p=0.1697$ ). As expected, lever pressing in the three treatment groups differed (Fig. $2 A$; two-way ANOVA with repeated measures over time: treatment, $F_{(2,609)}=91.33, p<0.0001$; time, $F_{(14,609)}=0.3788, p=$ 0.9806 ; interaction, $\left.F_{(28,609)}=0.8388, p=0.7060\right)$. Cocaine-SA rats pressed the active lever significantly more than saline-yoked or cocaine-yoked controls (Fig. $2 A$; cocaine-SA vs saline-Y, $t_{(609)}=$ $12.17, p<0.0001$; cocaine-SA vs cocaine-Y, $t_{(609)}=9.205, p<$ 0.0001 ; saline-yoked vs cocaine-Y, $\left.t_{(609)}=0.4642, p=0.9544\right)$. Self-administration training was followed by 14-19 d of Ext where neither cues nor drug was available. As previously reported in cocaine-SA-treated rats, the first day of extinction (Fig. $2 \mathrm{~A}$, vertical dashed line) was associated with a burst in lever pressing (Lerman and Iwata, 1995). As expected, rats trained for cocaine-SA showed stable context extinction of responding on the active levers (Fig. 2A).

Rats from the cocaine-SA and saline-yoked groups also underwent testing for cued reinstatement (Fig. 2B). Relapse to cocaine seeking was modeled in a session where cocaine-associated cues were presented, but lever pressing did not result in drug delivery (Kalivas and McFarland, 2003; McLaughlin and See, 2003). Responses to reinstatement testing differed between the saline-yoked and cocaine-SA groups (two-way ANOVA: treatment, $F_{(1,33)}=95.12, p<0.0001$; time, $F_{(1,33)}=105.6, p<$ 0.0001 ; interaction, $\left.F_{(1,33)}=61.57, p<0.0001\right)$. Lever pressing in the cocaine-SA group increased above that observed during the last day of extinction training (Fig. $2 B ; t_{(33)}=13.8, p<0.0001$ ). As predicted, rats in the saline-yoked group did not show increased lever pressing in response to light and tone cues (Fig. 2B; $\left.t_{(33)}=1.612, p=0.2194\right)$.

\section{Active (but not passive) exposure to cocaine suppresses dopamine-sensitive inhibition: experiment 1}

To determine whether cocaine self-administration causes acute changes in PL-PFC excitability, we killed animals $24 \mathrm{~h}$ after their last self-administration training session. In acute brain slices, we recorded layer $\mathrm{V}$ pyramidal neurons in the PFC in I-clamp to 
A

active
lever
inactive
lever
infusions
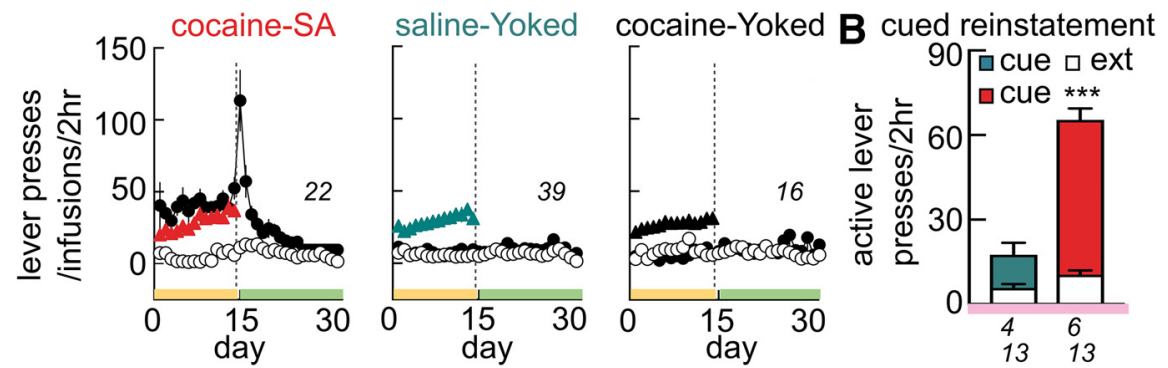

Figure 2. Behavioral responding in cocaine self-administration, yoked-cocaine, and yoked-saline rats. $\boldsymbol{A}$, Rats were presented with levers that resulted in the activation of a light and tone cue paired with the infusion of cocaine (cocaine-SA, $n=22$; left), passive infusion of saline (saline-yoked, $n=39$; middle), or passive infusion of cocaine (cocaine-yoked, $n=16$; right). The vertical dashed line on time courses indicates the switch from self-administration to extinction. In extinction sessions, lever pressing produced no infusions or cue presentations. Behavioral responses for voluntary cocaine self-administration extinguished in $14 \mathrm{~d}$. B, Re-exposure to drug-conditioned cues (without cocaine) significantly increased lever pressing in rats with a history of cocaine-SA. Numbers in italics represent the total number of animals. For these and all other figures, error bars indicate the mean \pm SEM. ${ }^{* * *} p \leq 0.0001$ compared with extinction using a Sidak test for multiple comparisons.

measure action potential firing to depolarizing current injections steps ( $0.8 \mathrm{~s}, 0.1-1 \mathrm{nA})$. We observed obvious differences in the firing responses among cocaine-SA, cocaine-yoked, and salineyoked treatment groups during the depolarizing current steps (Fig. 3B1, inset; two-way ANOVA with repeated measures over current: treatment, $F_{(2,76)}=34.89, p<0.0001$; current, $F_{(7,532)}=$ 62.94, $p<0.0001$; interaction, $\left.F_{(14,532)}=19.90, p<0.0001\right)$. A post hoc analysis showed no significant firing differences between the two yoked-treatment groups $(p=0.6400)$, but a significant increase in cocaine-SA responses relative to the cocaine-yoked group ( $p<0.0001$ ), which was surprising given that the two groups received similar amounts of cocaine (Fig. $2 A$ ). As prior reports show heterogeneous subpopulations of cortical neurons (Cruz et al., 2013, 2015), we used scatter plots to compare the relative distribution of individual firing responses at the $1 \mathrm{nA}$ current step. We categorized cell activity according to the degree of SFA, whereby SFA ${ }^{+}$neurons were classified as those showing five or fewer spikes during the final $500 \mathrm{~ms}$ of the $1 \mathrm{nA}$ current injection (Fig. 3B1). In most cocaine-SA neurons (81\%), training experience elevated firing (i.e., above the SFA threshold of five spikes; Fig. 3B1). By contrast, most firing responses in salineyoked (91\%) or noncontingent cocaine-yoked (79\%) groups displayed robust SFA (i.e., SFA ${ }^{+}$; Fig. $3 B 1$ ). The SFA is modulated by the AHP that follows a depolarization step (Madison and Nicoll, 1986). AHPs were measured following calibration of a $60 \mathrm{~ms}$ current injection step to yield a burst of five APs from a holding potential of $-70 \mathrm{mV}$ (Fig. $1 \mathrm{~B}$ ) and measured the total AHP area (Coulter et al., 1989; Moyer et al., 2000; Gu et al., 2005). As expected, after training, the AHP size decreased in the cocaine-SA group, but not in the yoked groups (Fig. 3B2; one-way ANOVA: treatment, $F_{(2,41)}=13.92, p<0.0001$; post hoc test: cocaine-SA vs saline-yoked, $p<0.0001$; cocaine-SA vs cocaine-yoked, $p=$ $0.0044)$. These data suggest that learning to lever press for cocaine and not the mere exposure to cocaine itself increases neuronal excitability.

In other cortical regions, activation of Kv7 voltage-gated $\mathrm{K}^{+}$ channels localized to the axon hillock suppresses neuronal output by enhancing SFA (Delmas and Brown, 2005; Lawrence et al., 2006; Brown and Passmore, 2009). To determine whether the cocaine-SA experience reduced this form of inhibition in PL-PFC cells, we sampled a range of membrane potentials in $V$-clamp $(-60$ to $-20 \mathrm{mV})$ to measure $I_{\mathrm{Kv} 7}$ values (Fig. $3 C 1$, inset). We observed that voltage-dependent $I_{\mathrm{Kv} 7}$ activated above $-50 \mathrm{mV}$ (Fig. 3C1). As with the previous firing measurements, the amplitude of $I_{\mathrm{Kv} 7}$ also differed significantly between the cocaine-SA and saline-yoked treatments (Fig. 3C1; two-way ANOVA with repeated measures of potential: treatment, $F_{(1,8)}=5.973, p<$ 0.0403 ; potential, $F_{(2,16)}=26.67, p<0.0001$; interaction, $F_{(4,32)}$ $=5.41, p<0.0019)$. When considering all cells sampled from the cocaine-SA and saline-yoked groups, the elevated basal level of firing at $1 \mathrm{nA}$ correlated with the reduction in $I_{\mathrm{Kv} 7}$ amplitudes (Fig. 3C2; $R^{2}=0.479$ ). Thus, at $24 \mathrm{~h}$ following the 2 weeks of cocaine self-administration, the loss of SFA may be due to functional suppression in Kv7 channel-mediated inhibition.

Our previous published work showed that bath application of dopamine or chemogenetic/optogenetic activation of VTA dopamine terminals suppressed SFA and AHPs in PL-PFC pyramidal cells (Buchta et al., 2017). Because repeated activation of cAMPcoupled GPCRs can sensitize adenylate cyclase to subsequently activate downstream signaling cascades (Johnston and Watts, 2003), we wondered whether dopamine suppresses SFA by closure of Kv7 channels and whether the repeated cocaine-SA impacted this function. To evaluate this, we sampled SFA, AHP, and $I_{\mathrm{Kv} 7}$ before and during the application of $10 \mu \mathrm{M}$ dopamine in the saline-yoked, cocaine-yoked, and cocaine-SA groups (Fig. $3 D, E)$. A two-way ANOVA using cell type as the betweensubjects factor and dopamine as a within-subject factor showed differences in both firing and AHPs (Fig. 3D1, firing: treatment, $F_{(2,15)}=3.83, p=0.0454$; dopamine, $F_{(1,10)}=58.64, p<0.0001$; interaction, $F_{(2,15)}=11.58, p=0.0009$; Fig. 3D2, AHP: treatment, $F_{(2,14)}=1.02, p=0.3860$; dopamine, $F_{(1,10)}=29.56, p<$ 0.0003 ; interaction, $\left.F_{(2,14)}=3.81, p=0.0477\right)$. At the $1 \mathrm{nA}$ current injection step, all but one of the sampled PL-PFC cells in the cocaine-SA group lacked SFA, whereas all cells in the salineyoked and cocaine-yoked groups displayed SFA (Fig. 3D1). In $\mathrm{SFA}^{+}$cells from both the saline-yoked and cocaine-yoked groups, dopamine increased firing responses and decreased AHPs relative to the predopamine levels (Tukey post-tests: Fig. $3 D 1$, firing: saline-yoked $/ \mathrm{SFA}^{+}, t_{(15)}=-4.56, p=0.0041$; cocaine-yoked/SFA ${ }^{+}, t_{(15)}=-7.37, p<0.0001$; Fig. 3D2, AHPs: saline-yoked, $t_{(14)}=3.90, p<0.0161$; cocaine-yoked, $t_{(14)}=$ 4.27, $p=0.0081)$. By contrast, firing and AHP responses in the $\mathrm{SFA}^{-}$cells of the cocaine-SA group were not measurably changed by dopamine (Fig. $3 D 1$; firing, $t_{(15)}=-1.03, p=0.9023$; Fig. 3D2; AHP: $\left.t_{(14)}=1.05, p=0.8920\right)$. This indicates an alteration in the regulation of intrinsic inhibition by dopamine in the population of SFA ${ }^{-}$cells.

Given the diminished sensitivity to dopamine in the firing and AHP experiments in the cocaine-SA group, we examined the dopamine action on evoked $I_{\mathrm{Kv} 7}$ currents in cells of the cocaine-SA group, all of which were SFA ${ }^{-}$(Fig. $3 E$ ). $I_{\mathrm{Kv} 7}$ responses to dopamine in cocaine-SA and saline-yoked treatments 
A

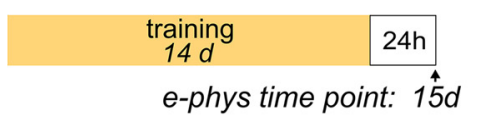

saline-yoked

- cocaine self administration
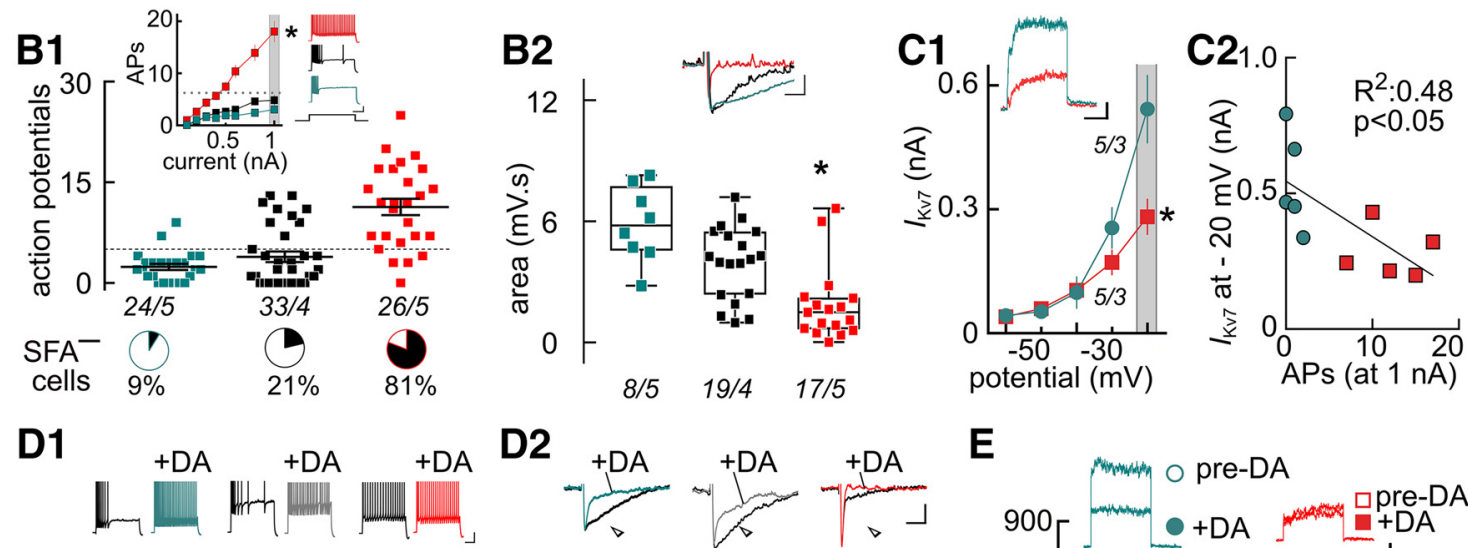

D2
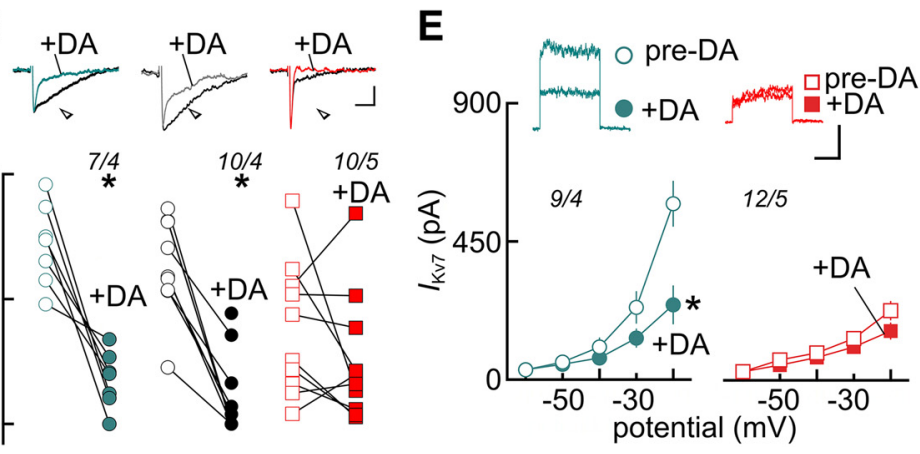

Figure 3. Experiment 1: training to self-administer cocaine (but not passive exposure to cocaine) suppressed intrinsic inhibition and inhibitory Kv7 channel currents. A, Timeline showing behavioral training ended $24 \mathrm{~h}$ before killing for electrophysiological recordings. B1, Scatter plots show firing responses of individual cells at $1 \mathrm{nA}$. Matching $\mathrm{I}-0$ curves (inset) show increased mean firing responses for the cocaine-SA relative to cocaine-yoked or saline-yoked treatment groups. Firing exceeded the upper limit for SFA (operationally defined as five or fewer spikes at $1 \mathrm{nA}$; dashed gray line) only in the cocaine-SA group. Black segments in the pie charts indicate the percentage of sampled cells that were SFA ${ }^{-}$. B2, Scatter plots show decreased average AHPs in the cocaine-SA group only. $C 1, I-0$ curves show reduced $I_{\text {KV7 }}$ currents in the cocaine-SA group. Before $I_{\text {Kv7 }}$ measurements, cells in the cocaine-SA and saline-yoked groups were confirmed to be SFA ${ }^{-}$and SFA ${ }^{+}$, respectively. (2), Reductions in $I_{\text {Kv7 }}$ current amplitudes correlated with AP firing at the $1 \mathrm{nA}$ step. D1, D2, Dot plot graphs show dopamine increased firing (D1) and decreased AHP (D2) in cocaine-SA/ $\mathrm{SFA}^{+}$and saline-yoked/SFA ${ }^{+}$cells. Dopamine produced no measurable change in cocaine-SA/SFA ${ }^{-}$cells. $E$, Dopamine reduced $I_{\mathrm{Kvy}}$ in the saline-yoked/SFA ${ }^{+}$but not in the cocaine-SA/SFA ${ }^{-}$ cells. All insets show sample traces collected at $1 \mathrm{nA} \mathrm{step} \mathrm{for} \mathrm{firing} \mathrm{(I-clamp)} \mathrm{or} \mathrm{at}-20 \mathrm{mV}$ for Kv7 (V-clamp). Italicized numbers represent the number of cells/animals. Calibration: $\boldsymbol{B}$ 1, $20 \mathrm{mV}, 0.2 \mathrm{~s}$; $\boldsymbol{B 2}, 3 \mathrm{mV}, 0.4 \mathrm{~s} ; \boldsymbol{C} 1,0.1 \mathrm{nA}, 0.4 \mathrm{~s} ; \mathbf{D 1}, 20 \mathrm{mV}, 0.2 \mathrm{~s} ; \mathbf{D 2}, 3 \mathrm{mV}, 0.5 \mathrm{~s} ; \boldsymbol{E}, 0.1 \mathrm{nA}, 0.4 \mathrm{~s} .{ }^{*} p \leq 0.01$ compared with saline-yoked animals using a Sidak test (B, C, $\left.\boldsymbol{E}\right)$ or a Tukey's test (D1, D2) for multiple comparisons. DA, Dopamine; e-phys, electrophysiological measurements.

differed significantly (two-way ANOVA with repeated measures of potential: treatment, $F_{(3,38)}=5.902, p=0.0021$; potential, $F_{(2,76)}=65.03, p<0.0001$; interaction, $F_{(6,76)}=8.949, p<$ $0.0001)$. To understand the nature of the interaction, we deconstructed individual treatment responses at $-20 \mathrm{mV}$, a potential where $I_{\mathrm{Kv} 7}$ was maximal. In support of our results above in Figure $3 C 1$, follow-up comparisons between treatments showed significantly reduced $I_{\mathrm{Kv} 7}$ amplitudes under baseline (predopamine) conditions in the cocaine-SA treatment group relative to salineyoked controls $(p<0.0001)$. Furthermore, dopamine reduced the $I_{\mathrm{Kv} 7}$ in the saline-yoked group $(p<0.0001)$, but not in the cocaine-SA group ( $p=0.6544 ;$ Fig. $3 E)$. In summary, the active self-administration (but not passive infusion) of cocaine was associated with a reduction in intrinsic inhibition, reduced sensitivity to dopamine, and suppression of inhibitory Kv7 ion channel currents.

\section{Dopamine-sensitive inhibition is suppressed after $14 \mathrm{~d}$ extinction training: experiment 2}

To determine whether the changes in PL-PFC excitability persisted after $14 \mathrm{~d}$ of extinction conditioning, rats were killed 15 min following the final extinction session (Fig. 4A). We excluded the cocaine-yoked group from further analysis since the previous experiment already showed that intrinsic inhibition was not altered by passive administration of cocaine, only by active self-administration of cocaine. We found that after extinction training, average firing responses were different between the cocaine-SA and saline-yoked control treatments (Fig. 4B1; twoway ANOVA with repeated measures of current: treatment, $F_{(1,66)}=5.309, p=0.0244$; current, $F_{(7,462)}=13.73, p<0.0001$; interaction, $\left.F_{(7,462)}=4.694, p<0.0001\right)$. Firing responses at a 1 $n A$ current step were elevated in the cocaine-SA group relative to those in saline-yoked controls $\left(t_{(528)}=4.372, p=0.0002\right)$. Approximately half $(57 \%)$ of cocaine-SA cells showed high firing (SFA $^{-}$responses), whereas only a minority $(11 \%)$ of salineyoked control cells were SFA ${ }^{-}$. Compared with training alone (without extinction; Fig. 3), there was a slight reduction in SFA ${ }^{-}$ cells (from $81 \%$ to $57 \%$ ) in the cocaine-SA group. Examination of individual cells showed evenly distributed responses in salineyoked treatments, but heterogeneous responses in the cocaine-SA treatments (Fig. 4B2), suggesting that only a subset of cells is persistently hyperactive after extinction training. AHP measurements following extinction showed similar changes; in the cocaine-SA treatment group, the mean value declined, but individual cells tended to cluster at higher or lower responses (Fig. $4 B 3$; unpaired $t$ test: $\left.t_{(80)}=3.898, p=0.0002\right)$. Together, these data suggest that following extinction a subpopulation of SFA ${ }^{-}$ cocaine-SA cells remain hypersensitive to depolarizing inputs.

To examine the involvement of Kv7 channels, first we measured the effects of the channel antagonist XE-991 (20 $\mu \mathrm{M}, 10 \mathrm{~min})$ 
A

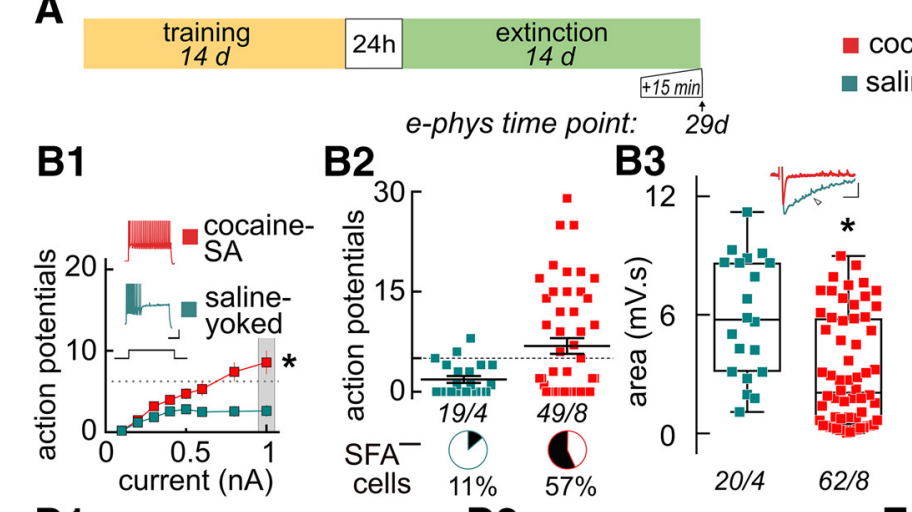

- cocaine self administration

saline-yoked
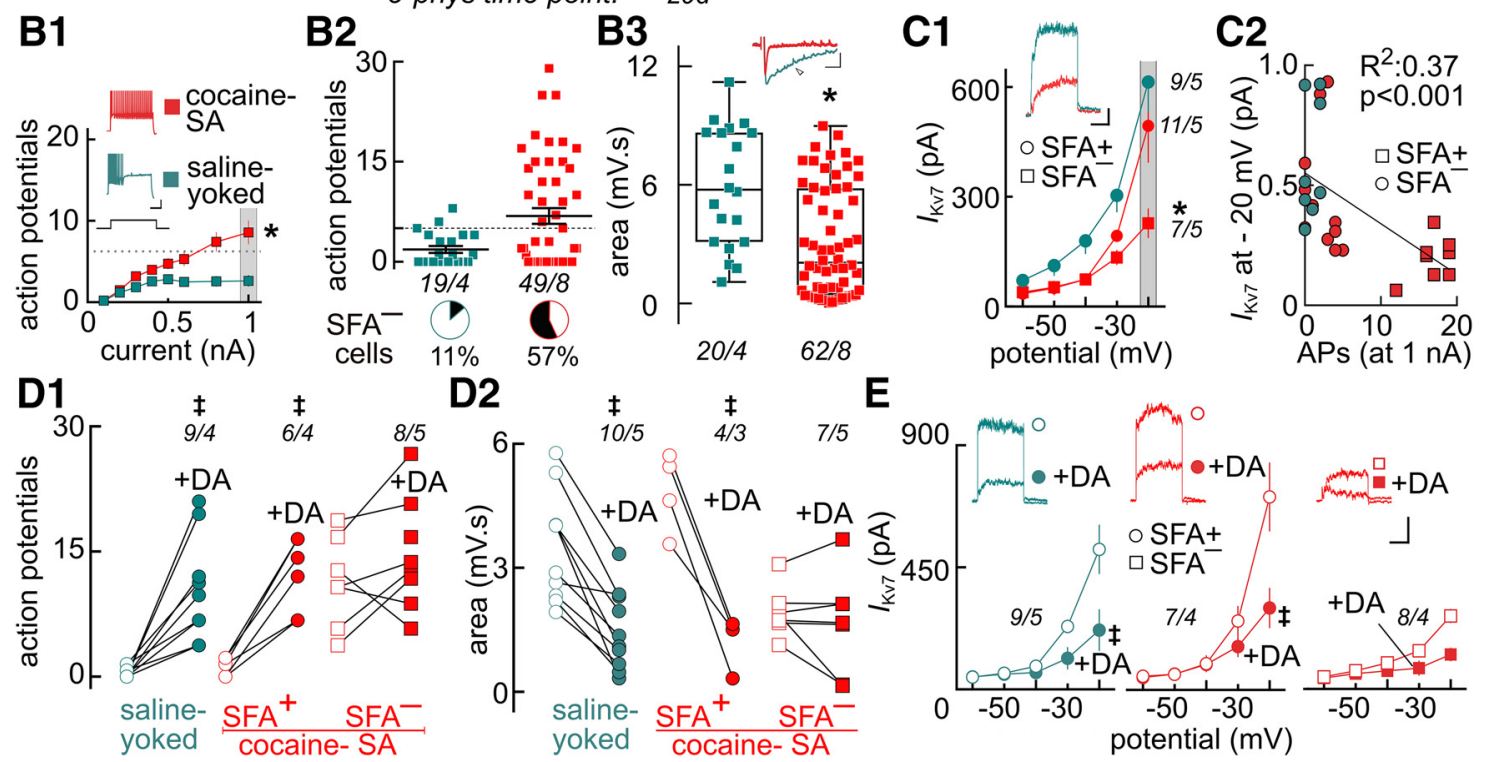

$E$

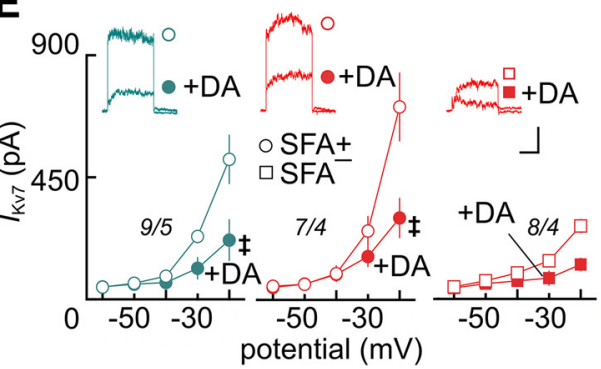

Figure 4. Extinguishing the behavioral responding for cocaine does not restore intrinsic inhibition or Kv7 channel currents. $A$, Timeline showing cocaine-SA (14 d) and extinction (14 d) before killing for electrophysiological recordings at $15 \mathrm{~min}$ after the final extinction session. $\boldsymbol{B 1}-\boldsymbol{B} 3$, Average firing $(\boldsymbol{B} 1,1-0$ curves) and individual firing (B2, scatter plots at $1 \mathrm{nA})$ were increased in the cocaine-SA group, while AHP ( $B 3$, scatter plots) was decreased relative to saline-yoked controls. Black segments in the pie charts indicate the percentage of sampled cells that were SFA ${ }^{-}$. $C 1, I-0$ curves show reduced $I_{\mathrm{Kv} 7}$ currents in the cocaine-SA/SFA ${ }^{-}$cells, but not the saline-yoked/SFA ${ }^{+}$or cocaine-SA/SFA ${ }^{+}$cells. $\mathbf{C 2}$, Reductions in $I_{\mathrm{Kv} 7}$ current amplitudes correlated with AP firing at the $1 \mathrm{nA}$ step. D1, D2, Dot plot graphs show that dopamine increased firing (D1) and decreased AHPs (D2) in SFA ${ }^{+}$cells from both saline-yoked and cocaine-SA groups. Dopamine did not measurably alter cocaine-SA/SFA ${ }^{-}$cells. E, Dopamine reduced $I_{\mathrm{Kv} 7}$ in SFA ${ }^{+}$cells of saline-yoked and cocaine-SA rats, but not in SFA ${ }^{-}$cells. All insets showing sample traces were collected at $1 \mathrm{nA}$ step for firing (I-clamp) or at $-20 \mathrm{mV}$ for Kv7 (V-clamp). Italicized numbers represent the number of cells/animals. Calibration: $\boldsymbol{B} 1,20 \mathrm{mV}, 0.2 \mathrm{~s} ; \boldsymbol{B} 3,3 \mathrm{mV}, 0.4 \mathrm{~s} ; \boldsymbol{C 1}, 0.1 \mathrm{nA}, 0.4 \mathrm{~s} ; \mathbf{D 1}, 20 \mathrm{mV}, 0.2 \mathrm{~s} ; \mathbf{D 2}, 3 \mathrm{mV}, 0.5 \mathrm{~s}$; $\boldsymbol{E}, 0.1 \mathrm{nA}, 0.4$ s. ${ }^{*} p \leq 0.001$ compared with saline-yoked animals using a Sidak test $(\boldsymbol{B}, \boldsymbol{C}, \boldsymbol{E})$ or a Tukey test $(\ddagger ; \boldsymbol{D})$ for multiple comparisons. DA, Dopamine; e-phys, electrophysiological measurements.

on firing frequency and second we measured the $I_{\mathrm{Kv} 7}$ value in voltage clamp in cells from the saline-yoked group and the population of SFA ${ }^{-}$cells from cocaine-SA rats immediately after the final extinction session. First, responses to XE-991 differed in saline-yoked $\mathrm{SFA}^{+}$cells and the subpopulation of SFA ${ }^{-}$cells from the cocaine-SA rats (two-way ANOVA with repeated measures of current: treatment, $F_{(3,30)}=17.89, p<0.0001$; current, $F_{(7,210)}=94.48, p<0.0001$; interaction, $F_{(21,210)}=10.23, p<$ 0.0001 ; data not shown). A subsequent analysis within the salineyoked group showed XE-991 increased firing across the full range of current steps, culminating in a 10-fold potentiation at the $1 \mathrm{nA}$ current step (two-way ANOVA with repeated measures of current: XE991, $F_{(1,112)}=42.42, p=0.0001$; current, $F_{(7,112)}=$ $10.06, p<0.0001$; interaction, $\left.F_{(7,112)}=6.971, p<0.0001\right)$. By contrast, the application of XE-991 did not alter the input-output curve for SFA ${ }^{-}$cells within the cocaine-SA group (two-way ANOVA with repeated measures of current: XE-991, $F_{(1,16)}=$ $0.5168, p=0.4826$; current, $F_{(7,112)}=95.73, p<0.0001$; interaction, $\left.F_{(7,112)}=0.8562, p=0.5435\right)$. A follow-up analysis of baseline (pre-XE-991) conditions comparing saline-yoked and cocaine-SA treatments at different current steps showed elevated action potential firing in the cocaine-SA (SFA ${ }^{-}$cells) group, indicating that firing may already be maximal and therefore less prone to further potentiation by blockade of Kv7 channels (twoway ANOVA with repeated measures of current: treatment, $F_{(1,15)}=42.82, p=0.0001$; current, $F_{(7,105)}=30.83, p<0.0001$; interaction, $\left.F_{(7,105)}=23.46, p<0.0001\right)$. Together, these data indicate that after extinction from cocaine self-administration, a population of PL-PFC cells show enhanced firing responses un- der baseline conditions and a related diminished sensitivity to Kv7 channel block.

Second, to corroborate these results, we measured $I_{\mathrm{Kv} 7}$ responses (Fig. 4C1, inset) in all cells across membrane potentials. We found significant differences among the three groups (salineyoked/SFA ${ }^{+}$, cocaine-SA/SFA ${ }^{+}$, and cocaine-SA/SFA ${ }^{-}$; Fig. 4C1; two-way ANOVA with repeated measures of potential: group/SFA, $F_{(2,29)}=8.669, p=0.0015$; potential, $F_{(2,48)}=58.94$, $p<0.0001$; interaction, $\left.F_{(4,48)}=4.344, p=0.0044\right)$. At $-20 \mathrm{mV}$, $I_{\mathrm{Kv} 7}$ responses in SFA ${ }^{-}$cells in the cocaine-SA group were reduced relative to the $\mathrm{SFA}^{+}$cells in the saline-yoked group (Fig. $4 C 1$; cocaine-SA/SFA ${ }^{+}$vs cocaine-SA/SFA ${ }^{-}: t_{(72)}=3.817, p=$ 0.0008 ; saline-Y/SFA ${ }^{+}$vs cocaine-SA/SFA ${ }^{-}: t_{(72)}=5.634, p<$ 0.0001 ; saline-yoked vs cocaine-SA/SFA ${ }^{+}: t_{(72)}=2.211, p=$ 0.0878 ). Similar to findings at $24 \mathrm{~h}$ after cocaine-SA, the basal level of firing at $1 \mathrm{nA}$ correlated with $I_{\mathrm{Kv} 7}$ amplitudes (Fig. 4C2; Ext, $R^{2}=0.370$ ). These results highlight an enduring functional shift in inhibition in a population of SFA ${ }^{-}$cells in the cocaine-SA group.

Given that dopamine regulates SFA in the PFC, we examined whether this regulation is altered following extinction (Fig. $4 D 1, D 2)$ and again noted differences between the groups in both firing and AHPs (firing: treatment, $F_{(2,8)}=4.78, p=0.0432$; dopamine, $F_{(1,9)}=26.69, p<0.0006$; interaction, $F_{(2,8)}=6.27$, $p=0.0230$; AHP: treatment, $F_{(2,7)}=3.08, p=0.1097$; dopamine, $F_{(1,8)}=57.20, p<0.0001$; interaction, $\left.F_{(2,7)}=12.18, p=0.0053\right)$. In SFA ${ }^{+}$cells of either saline-yoked or cocaine-SA rats, bath application of dopamine $(10 \mu \mathrm{M}, 10 \mathrm{~min})$ produced robust changes in SFA and AHPs (Tukey post-test; Fig. 4D1, saline- 
yoked $/ \mathrm{SFA}^{+}: t_{(8)}=-4.59, p=0.0151$; cocaine-SA/SFA ${ }^{+}: t_{(8)}=$ $-4.06, p=0.0293$; Fig. 4D2, saline-yoked/SFA ${ }^{+}: t_{(7)}=6.25, p<$ 0.0036 ; cocaine-SA/SFA $\left.{ }^{+}: t_{(7)}=5.83, p=0.0053\right)$. In contrast, in $\mathrm{SFA}^{-}$cells (only observed in the cocaine-SA group) there was no measurable dopamine-induced change in firing or AHPs (Tukey post-test; Fig. $4 D 1$, cocaine-SA/SFA ${ }^{+}: t_{(8)}=-0.18, p=1.0000$; Fig. $4 D 2$, AHP: $\left.t_{(7)}=0.90, p=0.9356\right)$.

Correspondingly, responses of inhibitory Kv7 currents to dopamine also differed between treatment groups (Fig. 4E; two-way ANOVA with repeated measures of potential, treatment $F_{(5,42)}=$ $5.025, p=0.0011$; potential $F_{(2,84)}=75.74, p=0.0001$; interaction: $\left.F_{(10,84)}=7.968, p<0.0001\right)$. This difference could be explained, in a subsequent analysis, by the finding that most cells in the saline-yoked group were SFA ${ }^{+}$. However, in both the salineyoked/SFA ${ }^{+}$and cocaine-SA/SFA ${ }^{+}$groups, dopamine reduced $I_{\mathrm{Kv} 7}$ amplitudes (two-way ANOVA with repeated measures of potential: saline-yoked/SFA ${ }^{+}$, dopamine $F_{(1,16)}=6.534, p=$ 0.0201 ; potential $F_{(2,32)}=28.37, p=0.0001$; interaction: $F_{(2,32)}=$ $6.185, p<0.0054$; cocaine-SA/SFA ${ }^{+}$, dopamine $F_{(1,12)}=5.646$, $p=0.0350$; potential $F_{(2,24)}=31.5, p=0.0001$; interaction: $\left.F_{(2,24)}=7.927, p=0.0023\right)$. In contrast, dopamine did not alter $I_{\mathrm{Kv} 7}$ amplitudes in cocaine-SA/SFA ${ }^{-}$cells (Fig. 4E; two-way ANOVA with repeated measures of potential: dopamine, $F_{(1,14)}=$ 3.695, $p=0.0752$; potential, $F_{(2,28)}=19.44, p<0.0001$; interaction, $\left.F_{(2,28)}=9.973, p<0.0005\right)$. A final comparison of the baseline (pre-dopamine, $-20 \mathrm{mV}$ ) conditions among the three groups showed significantly reduced $I_{\mathrm{Kv} 7}$ amplitudes in the cocaine-SA/SFA ${ }^{-}$group relative to cocaine-SA/SFA ${ }^{+}$cells (Fig. $4 E$; one-way ANOVA, $F_{(2,21)}=3.653, p=0.0435$; post hoc salineyoked $/ \mathrm{SFA}^{+}$vs cocaine-SA/SFA ${ }^{+}: t_{(21)}=1.578, p=0.3404$; post hoc saline-yoked $/ \mathrm{SFA}^{+}$vs cocaine-SA/SFA ${ }^{-}: t_{(21)}=1.936, p=$ 0.1865 ; cocaine-SA/SFA ${ }^{+}$vs cocaine-SA/SFA ${ }^{-}: t_{(21)}=3.354$, $p=0.0090$ ). This suggests that the baseline amplitude of $I_{\mathrm{Kv} 7}$ in cocaine-SA/SFA ${ }^{-}$cells was already reduced before bath application of dopamine. Together, these data indicate that after 2 weeks of cocaine self-administration a population of SFA ${ }^{-}$cells experience a reduction in intrinsic inhibition and therefore reduced sensitivity to dopamine regulation, and that this relationship persists even after the behavioral extinction of drug-paired associations.

Inhibition following withdrawal from cocaine-SA or sucroseSA with extinction training: experiment 3

Typically, reductions in intrinsic inhibition are transient, learning specific, and behaviorally appropriate (Oh and Disterhoft, 2015). To determine whether extinction learning is required for the enduring reduction in intrinsic inhibition in the cocaine-SA/ $\mathrm{SFA}^{-}$population, we sampled cells from cocaine-SA animals that did not undergo extinction training, but instead underwent $14 \mathrm{~d}$ of home-cage withdrawal (Fig. 5A). Like the firing responses in extinguished animals (Fig. $4 B$ ), average firing responses in approximately half of cells in the withdrawal group exceeded the maximal limit for SFA, and the individual responses for firing and AHPs clustered at high and low values (Fig. 5A). This indicates that intrinsic inhibition is also modified in cocaine-SA animals that did not experience extinction training. In addition, we killed a group of naive animals without any prior experience of handling and surgery. Cells from naive rats displayed firing and AHP responses (Fig. 5B) qualitatively identical to those observed after saline-yoked treatment (Fig. $4 B$ ). This indicates that the cocaine-SA-induced adaption in intrinsic inhibition in the PFC did not require extinction training or the handling associated with the surgical procedures.
Self-administration of sucrose can modify some of the same brain reward circuitry stimulated by drugs of abuse (McGlinchey et al., 2016). We next determined whether sucrose, a nondrug reinforcer, produced adaptations in intrinsic inhibition in the PFC similar to those observed after cocaine self-administration. Rats trained to self-administer sucrose pellets paired with light/ tone cues (Fig. 5C1) for 10-14 d showed stable lever pressing (Fig. 5C2). During extinction conditions (Ext, 14-19 d) when neither cues nor sucrose was available, lever-press responding diminished as expected (Fig. 5C2). To evaluate firing and AHP responses, rats were killed either at $24 \mathrm{~h}$ after the final selfadministration training session (training; day 15) or immediately after the final extinction (Ext; day 29). Firing responses in the sucrose-SA rats after training and extinction differed (Fig. 5C3; two-way ANOVA with repeated measures of current: treatment, $F_{(1,45)}=5.525, p=0.0232$; current, $F_{(7,315)}=20.97, p<0.0001$; interaction, $\left.F_{(7,315)}=4.921, p<0.0001\right)$. After training, approximately half of the sampled sucrose-SA cells showed elevated firing $\left(\mathrm{SFA}^{-}\right.$, 56\%; Fig. 5C4), which is a much lower proportion than we observed after cocaine-SA training (Fig. 3B1, 81\%). In contrast, following extinction, few cells in the sucrose-SA group showed elevated firing (Fig. 5C4, SFA ${ }^{-}, 14 \%$ ). In fact, sucrose-SA responses after extinction more resembled those described previously in the saline-yoked with extinction rats (Fig. $4 B, 11 \%$ ) or in naive rats (Fig. 5B,5\%), and did not resemble responses in the cocaine-SA extinction group (Fig. 4B2, 57\%). AHPs in the sucrose-SA rats after training and extinction also differed (Fig. $5 C 5$; unpaired $t$ test: $\left.t_{(41)}=6.876, p<0.0001\right)$. AHP responses in the sucrose-SA with extinction group resembled responses in the saline-yoked with extinction (Fig. $4 B$ ) or in naive rats (Fig. $5 B$, $5 \%$ ), and diverged from AHP responses in the cocaine-SA extinction group (Fig. 4B3). Together, this indicates that training to self-administer drug (cocaine) and nondrug (sucrose) reinforcers produces qualitatively similar reductions in intrinsic inhibition early on, but for drug reinforcers these modifications are persistent even after withdrawal or extinction. These data are consistent with those of previous studies reporting that drug and nondrug reinforcers produce different cellular adaptations in PLPFC neurons (Whitaker et al., 2017).

\section{Stabilization of Kv7-mediated inhibition suppresses cued-reinstatement: experiment 4}

To determine whether a loss of intrinsic inhibition contributes to relapse and to what extent the stabilization of inhibitory Kv7 channels would reduce relapse, we measured responses in rats 15 min after a 2 h cue-reinstatement session (Fig. 6A). Following cued reinstatement testing (Fig. 2B), the cocaine-SA group showed robust differences in firing from saline-yoked controls (Fig. 6B1; two-way ANOVA: treatment, $F_{(1,43)}=34.22, p<$ 0.0001 ; current, $F_{(7,301)}=36.09, p<0.0001$; interaction, $F_{(7,301)}$ $=23.16, p<0.0001)$. A post hoc analysis showed elevated firing ( $\mathrm{SFA}^{-}$responses) in the cocaine-SA group (1 nA current step: $\left.t_{(344)}=10.68, p<0.0001\right)$. Although after cue testing most cocaine-SA cells ( $72 \%$ ) showed this firing response, only a minority (11\%) of saline-yoked controls were SFA ${ }^{-}$(Fig. 6B2). Although visual inspection of dot plots depicting individual cell AHP responses in cocaine-SA and saline-yoked groups showed an apparent divergent distribution of responses in the cocaine-SA group (Fig. $6 B 3$ ), the difference in the average AHP between groups did not reach statistical significance (Fig. $6 B 3$; $t$ test: treatment, $t_{(41)}=1.847$, $p=0.0720)$. Thus, cued reinstatement is associated with potentiated firing responses in $\mathrm{SFA}^{-}$cells from rats with extinguished behavioral responding for cocaine self-administration. 
A

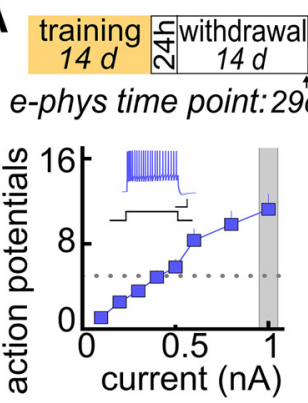

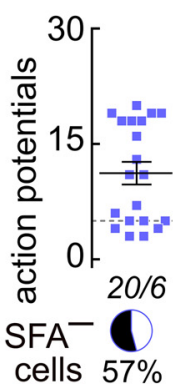

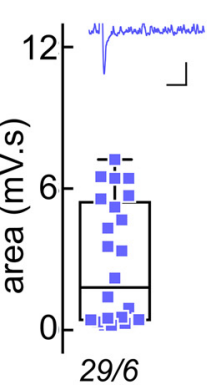

B
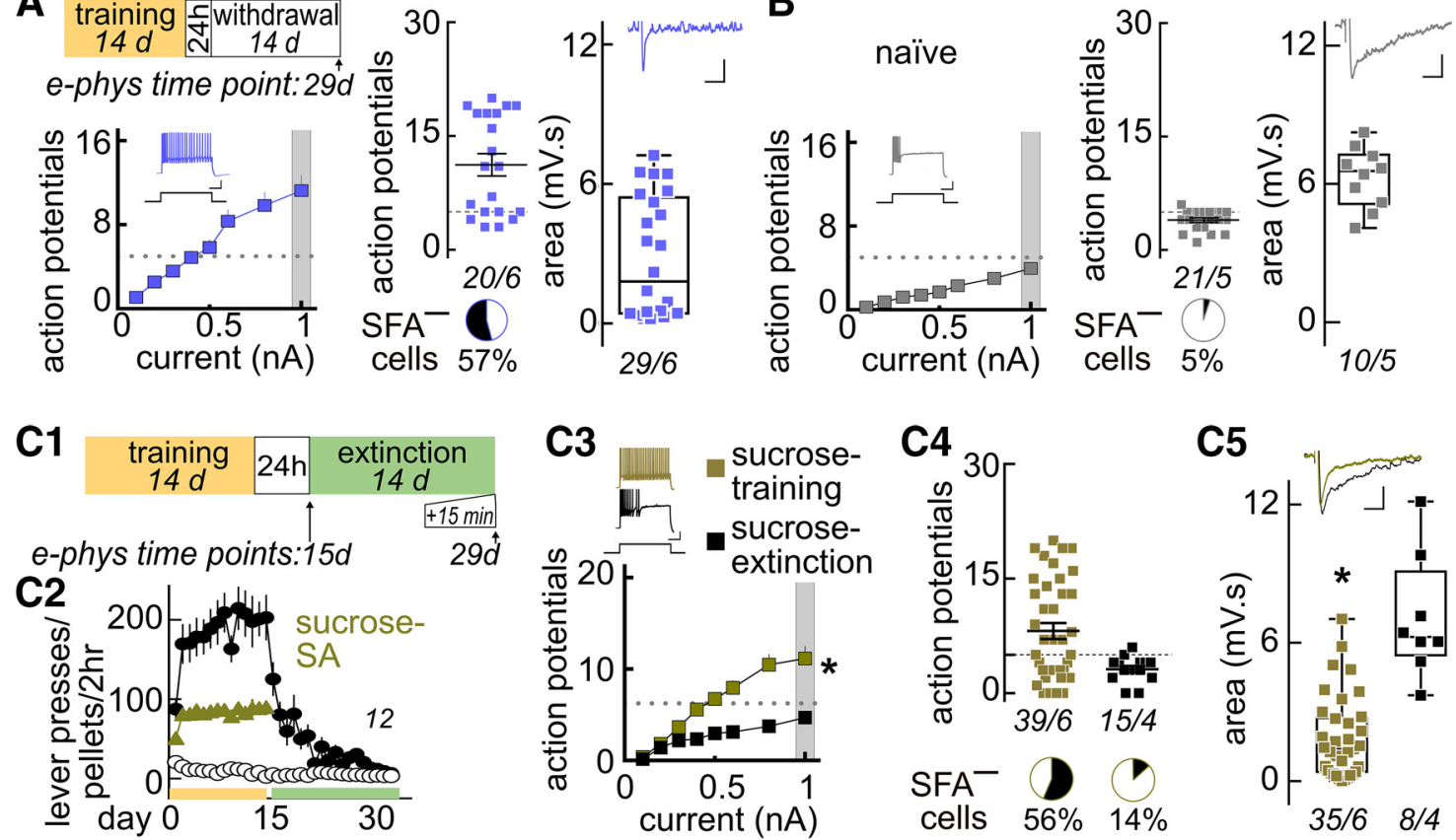

Figure 5. Differences in intrinsic inhibition following withdrawal from cocaine-SA and behavioral extinction from sucrose-SA. $A$, Top, Timeline showing cocaine-SA with $14 \mathrm{~d}$ of home-cage withdrawal, ending immediately before the preparation of brain slices for electrophysiological recordings (e-phys). Cells from rats withdrawn from cocaine-SA (without extinction training) showed elevated average firing beyond the maximal range for SFA (I- 0 curve with inset sample trace collected at $1 \mathrm{nA}$ ), heterogeneous individual firing responses (scatter plots at $1 \mathrm{nA}$ ), and reduced AHPs (inset, sample trace and scatter plots). $\boldsymbol{B}$, Responses from unhandled, experimentally naive rats showed robust SFA across the I- 0 curve and homogeneous individual firing (scatter plots at $1 \mathrm{nA}$ ) and AHP (scatter plots) responses. C1, Timeline showing $14 \mathrm{~d}$ of sucrose-SA followed by extinction (14 d). Preparation of brain slices occurred at either $24 \mathrm{~h}$ after the last SA session (day 15) or $15 \mathrm{~min}$ after the final extinction session (day 29). (2, Rats were presented with levers that resulted in the activation of a light and tone cue paired with the delivery of a sucrose pellet. The vertical dashed line on time courses indicates the switch from self-administration to extinction. In extinction sessions, lever pressing had no consequence. Behavioral responses for sucrose extinguished in $14 \mathrm{~d}$. C3-C5, Comparison of responses showing the increased excitability associated with sucrose-SA resolves with extinction, including average firing (C3, I- 0 curves), individual firing responses (C4, scatter plot, at $1 \mathrm{nA})$, and AHPs ( $\mathbf{C 5}$, scatter plot). The black segments in the pie charts indicate the percentage of sampled cells that were SFA ${ }^{-}$. Italicized numbers indicate the number of cells/animal. Calibration: $A, B, C$, firing traces, $20 \mathrm{mV}, 0.2 \mathrm{~s} ; A, B, C$, AHP traces, $3 \mathrm{mV}, 0.4 \mathrm{~s} .{ }^{*} p \leq 0.001$ compared with sucrose-extinction using a Sidak test for multiple comparisons or unpaired $t$ test.

Because changes in SFA responses following reinstatement testing exceeded those following extinction, we determined whether cued reinstatement exposure also suppressed the function of Kv7 channels (Fig. 6C). A comparison of $I_{\mathrm{Kv} 7}$ function after cued reinstatement testing showed obvious differences between the $\mathrm{SFA}^{+}$cells (from both the saline-yoked and cocaine-SA groups) and SFA ${ }^{-}$cells in the cocaine-SA group (Fig. $6 C$; two-way ANOVA with repeated measures of potential: treatment, $F_{(2,29)}=9.064, p=0.0006$; potential, $F_{(2,58)}=80.98, p<$ 0.0001 ; interaction, $\left.F_{(4,58)}=7.272, p<0.0001\right)$. A post hoc analysis of responses at $-20 \mathrm{mV}$ indicated no difference in $I_{\mathrm{Kv} 7} \mathrm{am}$ plitude between $\mathrm{SFA}^{+}$cells from saline-yoked and cocaine-SA rats (Fig. $6 C ; t_{(87)}=0.8783, p=0.7673$ ), but a significant reduction of $I_{\mathrm{Kv} 7}$ amplitudes in the $\mathrm{SFA}^{-}$cell population (Fig. $6 \mathrm{C}$; cocaine-SA/SFA ${ }^{-}$vs cocaine-SA/SFA ${ }^{+}: t_{(87)}=4.718, p<$ 0.0001 ; cocaine-SA/SFA ${ }^{-}$vs saline-yoked/SFA ${ }^{+}: t_{(87)}=6.166$, $p<0.0001)$. Thus, the function of Kv7 channels is suppressed in $\mathrm{SFA}^{-}$cells following re-exposure to drug paired cues that reinstate drug seeking.

To determine whether the stabilization of Kv7 channels with retigabine could restore SFA and $I_{\mathrm{Kv} 7}$ in neurons from cocaineSA-experienced animals, two types of experiments were performed. In the first experiment, current-clamp recordings were conducted in slices prepared at $15 \mathrm{~min}$ after a $2 \mathrm{~h}$ cue test to sample firing both before and after bath application of retigabine (20 $\mu \mathrm{M}, 10 \mathrm{~min})$. Firing responses in the saline-yoked and cocaine-SA treatments differed considerably at this time point (Fig. $6 D$; two-way ANOVA: treatment, $F_{(3,34)}=22.44, p=0.0001$; current, $F_{(7,238)}=$ $9.626, p=0.0001$; interaction, $\left.F_{(21,238)}=14.49, p<0.0001\right)$. A post hoc analysis of the retigabine action measured at the $1 \mathrm{nA}$ current step indicated no measurable retigabine effect on firing in SFA ${ }^{+}$ cells from saline-yoked rats $\left(t_{(272)}=0.1590, p>0.9999\right)$, but a robust retigabine-mediated reduction of firing in $\mathrm{SFA}^{-}$cells from cocaine-SA rats $\left(t_{(272)}=14.2, p<0.0001\right)$. Presumably, the nominal response of controls to retigabine reflected strong preexisting intrinsic inhibition, whereas the pronounced retigabine action across the full range of current injections in $\mathrm{SFA}^{-}$cells in cocaine-SA rats reflected a pre-existing state of weakened Kv7 channel-mediated inhibition.

To test this notion, a second group of experiments determined whether exposure to drug-paired cues reduced Kv7 channel inhibition and to what extent the reduction was rescued by retigabine. Following the cued reinstatement test, $I_{\mathrm{Kv} 7}$ currents were measured before and after bath application of retigabine $(20 \mu \mathrm{M}$, $10 \mathrm{~min})$. Retigabine responses in SFA ${ }^{+}$cells from saline-yoked controls and SFA ${ }^{-}$cells from cocaine-SA rats differed (Fig. 6E; two-way ANOVA; treatment, $F_{(3,32)}=5.503, p=0.0037$; potential, $F_{(2,64)}=81.19, p<0.0001$; interaction, $F_{(6,64)}=3.559, p=$ 0.0042 ). Subsequent analysis showed that retigabine increased the amplitude of $I_{\mathrm{Kv} 7}$ in SFA ${ }^{-}$cells from cocaine-SA rats $\left(t_{(96)}=\right.$ $1.672, p=0.0138)$ without significantly altering the $I_{\mathrm{Kv} 7}$ responses in SFA ${ }^{+}$cells from saline-yoked rats $\left(t_{(96)}=1.672, p=\right.$ 0.4609). This indicates that retigabine partially restored Kv7 channel inhibition to SFA ${ }^{-}$cells from cocaine-SA rats, but, in contrast, produced little measurable change in neurons with normal pre-existing levels of intrinsic inhibition.

Cue-induced reinstatement of cocaine seeking is blocked by reversible pharmacological or chemogenetic/optogenetic inacti- 
A

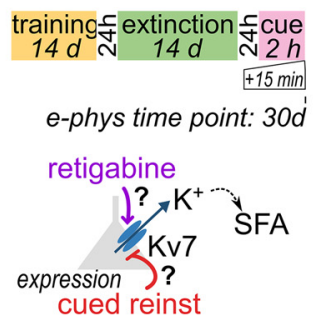

B1

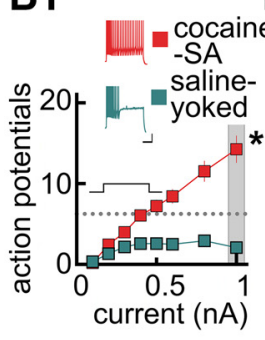

B2

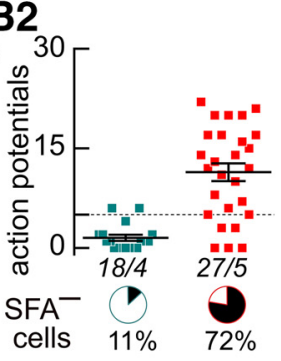

B3

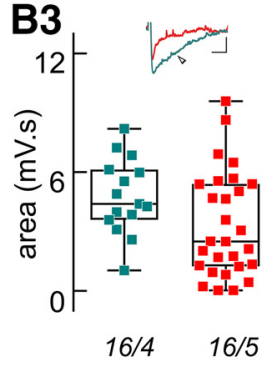

C

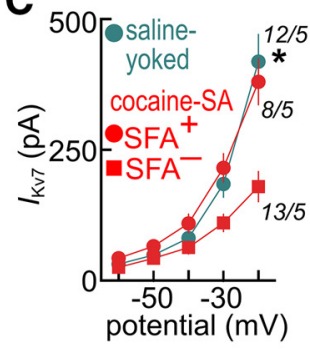

cocaine
-SA
saline-
yoked
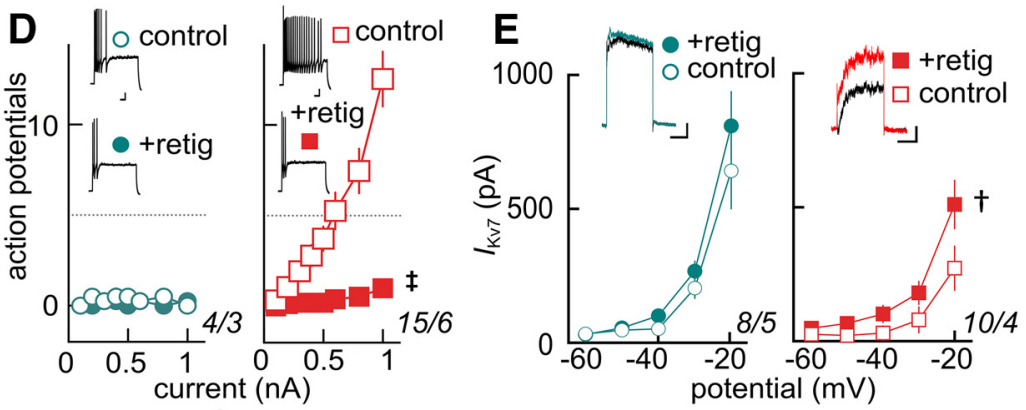

F 80 cued reinstatement G

G saline-yoked cocaine-SA
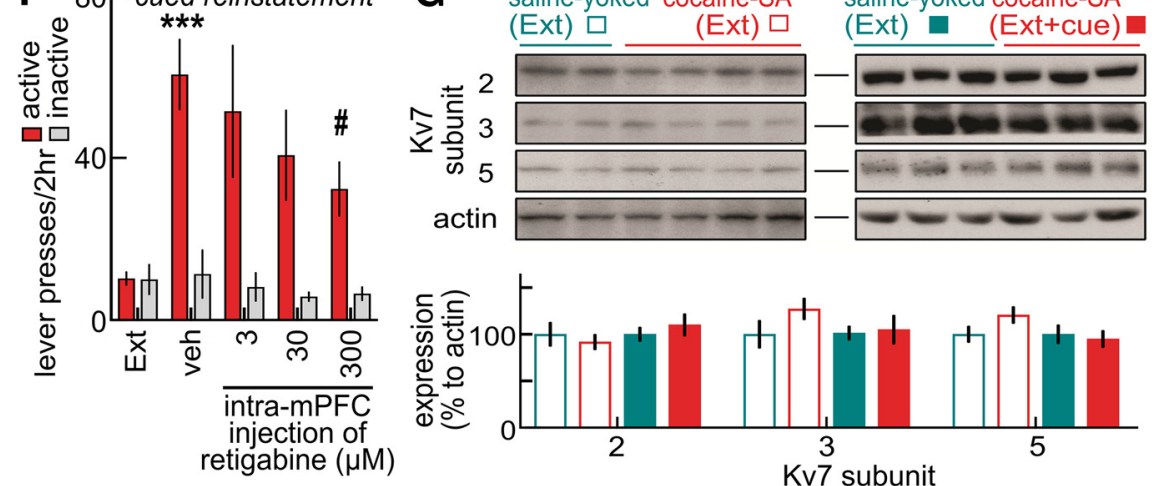

Figure 6. Cues that reinstate cocaine seeking rekindle the suppression of intrinsic inhibition: Restoration of inhibition by stabilization of Kv7 channels reduces cocaine seeking. $\boldsymbol{A}$, Timeline showing the preparation of brain slices, occurring $15 \mathrm{~min}$ after the $2 \mathrm{~h}$ cued reinstatement test. Diagram shows proposed retigabine (retig) action on $/ \mathrm{Kv} 7$ in SFA ${ }^{-}$cells during reinstatement. B1-B3, Comparison of responses showing cued reinstatement reduces intrinsic inhibition in cocaine-SA treatments relative to saline-yoked controls. Shown are average firing (B1, I-0 curves), individual firing responses (B2, scatter plot, at $1 \mathrm{nA}$ ), and AHPs (B3, scatter plot). Black segments in pie charts below indicate the percentage of sampled cells that were SFA ${ }^{-}$. C, Relative to SFA ${ }^{+}$(cocaine-SA or saline-yoked) cells, $I_{\mathrm{Kv} 7}$ currents are reduced in SFA ${ }^{-}$(cocaine-SA) cells. $\boldsymbol{D}, \boldsymbol{E}$, Summary graphs showing retigabine $(20 \mu \mathrm{M})$ reduced firing $(\boldsymbol{D})$ and increased $I_{\mathrm{Kv7}}(\boldsymbol{E})$ only in SFA ${ }^{-}($cocaine-SA) cells, and not in SFA ${ }^{+}$(saline-yoked and cocaine-SA) cells. $F$, Bilateral microinjection of retigabine into PL-PFC 10 min before reinstatement testing resulted in a dose-dependent reduction of cue-induced reinstatement. G, Western blots of PL-PFC punch lysates showing Kv7 subunit expression $(7.2,7.3,7.5)$ as a percentage of actin control did not differ between saline-yoked and cocaine-SA, either after extinction or after cued reinstatement. Calibration: $\boldsymbol{B} 1, \mathbf{D}, 20 \mathrm{mV}, 0.2 \mathrm{~s} ; \boldsymbol{B} 3,3 \mathrm{mV}, 0.4 \mathrm{~s} ; \boldsymbol{C} \mathbf{E}, \boldsymbol{E}, 0.1 \mathrm{nA}, 0.4 \mathrm{~s}$. All insets showing sample traces were collected at the $1 \mathrm{nA}$ step for firing (I-clamp) or at $-20 \mathrm{mV}$ for Kv7 (V-clamp). Italicized numbers indicate the cells/animal. Sidak test for multiple comparisons: $p \leq 0.0001$ compared with saline-yoked (*; $\boldsymbol{B}$, $\boldsymbol{C}$ ) or preretigabine $(\ddagger ; \boldsymbol{D}) ; p \leq 0.01$ compared with preretigabine $(\dagger ; \boldsymbol{E}) . \boldsymbol{F}^{* * *} p \leq 0.0001$, vs ext; $\# p=0.0299$, vehicle vs retig $(300 \mu \mathrm{M})$. e-phys, Electrophysiological recordings; vehicle, veh.

vation of cells in the PL-PFC or their terminals in the nucleus accumbens (Kalivas and McFarland, 2003; Gipson et al., 2013, 2014; Stefanik et al., 2016). It is possible that the drug-paired cues activated PL-PFC cells with reduced intrinsic inhibition, thus causing enhanced firing that promotes cocaine seeking. To determine whether the stabilization of inhibitory PL-PFC Kv7 channels would reduce cued reinstatement of cocaine-seeking behavior, we used a counterbalanced design using cocaine-SA rats that were extinguished from cocaine seeking and microinjected retigabine or vehicle directly into PL-PFC region $10 \mathrm{~min}$ before reinstatement testing. Infusions altered the average leverpressing behavior for drug-associated cues (Fig. 6F; two-way ANOVA: concentration, $F_{(4,110)}=5.561, p=0.0004$; lever, $F_{(1,110)}=56.64, p<0.0001$; interaction, $F_{(4,110)}=5.504, p=$ $0.0004)$. A post hoc comparison of pressing between the last extinction session and the cue session showed potentiated active lever pressing in vehicle-injected animals (Fig. $6 F ; t_{(110)}=6.233$, $p<0.0001)$. The magnitude of the reinstatement was compara- ble to what we observed in our earlier experiments (Fig. 2B) and consistent with previous reports (Venniro et al., 2016). Relative to vehicle infusions, retigabine dose-dependently reduced the reinstatement of active lever pressing significantly at $300 \mu \mathrm{M}$ (Fig. $6 G ; 3 \mu \mathrm{M}, t_{(110)}=0.8641, p=0.9928 ; 30 \mu \mathrm{M}, t_{(110)}=2.073, p=$ $\left.0.3387 ; 300 \mu \mathrm{M}, t_{(110)}=3.036, p=0.0295\right)$. A comparison of the total distance traveled by the same rats in a novel chamber locomotion test did not show significant differences caused by retigabine in any of the treatment groups (one-way ANOVA comparing vehicle, retigabine $(30 \mu \mathrm{M})$, and retigabine $(300 \mu \mathrm{M}): F_{(2,33)}=0.5745, p=$ $0.5685)$, suggesting that the retigabine action on reinstatement was not due to a nonspecific reduction in motor behavior. The cannula placements for PL-PFC microinjections were verified histologically in all animals included in the analysis.

To determine whether these cocaine experiences altered the protein expression of Kv7 channel subunits, separate groups of saline-yoked and cocaine-SA rats were killed $15 \mathrm{~min}$ after the $2 \mathrm{~h}$ reinstatement test for a Western blot analysis (Fig. 6G). A com- 
parison of the PL-PFC tissue homogenates showed no differences in the expression levels of the three principle subunits of the neuronal Kv7 family (Kv7.2, Kv7.3, and Kv7.5; Fig. 5G; two-way ANOVA: treatment, $F_{(3,84)}=0.6641, p=0.5764$; subunits, $F_{(2,84)}=$ $0.3579, p=0.7002$; interaction, $\left.F_{(6,84)}=7699, p=0.5957\right)$. Together, these results suggest that rather than reducing Kv7 channel expression, the operant training for cocaine desensitizes the function of inhibitory Kv7 channels. Thus, by stabilizing the open state of Kv7 channels, retigabine reduces cue-induced reinstatement of cocaine seeking when injected into the PL-PFC.

\section{Reduced inhibition in cFos-GFP ${ }^{+}$, but not cFos-GFP ${ }^{-}$cells: experiment 5}

The experiments above used a generalized selection criterion of PL-PFC neurons based on location, morphology, and electrophysiological parameters to show that re-exposure to drugconditioned cues to reinstate drug seeking also rekindled the reduction in intrinsic inhibition that emerges after cocaine selfadministration. This occurred in the majority of SFA ${ }^{-}$cells, despite the extinction of behavioral responding for cocaine. Because published studies have shown a causal link between the persistent expression of cocaine-related behaviors and the activation of select ensembles of neurons following re-exposure to drugassociated cues and context (Koya et al., 2009; Bossert et al., 2011; Fanous et al., 2012; Bobadilla et al., 2017), we evaluated whether the PL-PFC neurons with reduced inhibition represented a similar engram. Behaviorally relevant ensembles of cells have been identified in behaviorally activated cFos-GFP transgenic rats, where activation of the $\mathrm{c}$-fos promoter drives the expression of green fluorescent protein (cFos-GFP; Fig. 7A; Koya et al., 2012). Using the same line of transgenic animals, we determined whether the expression of Fos paralleled the cocaine-SA modification in intrinsic inhibition.

Transgenic rats underwent self-administration training for cocaine or yoked infusion of saline followed by extinction (Fig. $7 B$ ) and cued reinstatement (Fig. 7C). No differences in the total number of drug or saline infusions were found between the group of transgenic rats and the wild-type rats examined above in Figure $2 A$ (one-way ANOVA: $F_{(3,90)}=0.3502, p=0.7891$ ). Similar to the above responses in wild-type rats (Fig. $2 A$ ), transgenic rats trained to self-administer cocaine pressed the active lever significantly more than saline-yoked controls (Fig. 7B; two-way ANOVA with repeated measures over time: treatment, $F_{(1,16)}=$ $21.89, p=0.0003$; time, $F_{(13,208)}=1.221, p=0.2661$; interaction, $\left.F_{(13,208)}=1.963, p=0.0253\right)$. Active lever pressing for drug was extinguished over 2 weeks of extinction training (Fig. $7 B$ ). The responses to reinstatement testing differed between the salineyoked and cocaine-SA groups (two-way ANOVA: treatment, $F_{(1,25)}=34.56, p<0.0001$; time, $F_{(1,25)}=35.38, p<0.0001$; interaction, $\left.F_{(1,25)}=38.10, p<0.0001\right)$. Lever pressing in the transgenic cocaine-SA group increased above that observed during the last day of extinction training (Fig. $7 C$; $t_{(25)}=8.649, p<$ $0.0001)$. As predicted, rats in the transgenic saline-yoked group did not show increased lever pressing in response to light and tone cues (Fig. $7 C ; t_{(25)}=0.1576, p=0.9846$ ).

To corroborate previous reports validating the transgene, one rat from each of the saline-yoked and the cocaine-SA training groups received cardiac perfusion $15 \mathrm{~min}$ following the first extinction session (day 15) for subsequent immunofluorescent evaluation. This time point is associated with a burst of leverpressing activity in cocaine-SA rats (Fig. 7B). The GFP fluorescence levels in fixed sections visualized on a confocal microscope showed a high degree of overlap of cFos-GFP and endogenous immunolabeled Fos (Fig. 7D1,D2), which is consistent with other published work (Koya et al., 2012). A similar group of animals killed immediately following the final extinction session (day 30) showed qualitatively similar $\mathrm{GFP}^{+}$cells in living brain slices when evaluated on a confocal microscope (Fig. 7E1). Cells from living brain slices collected at the same time point (day 30) were also suitable for high-magnification ex vivo electrophysiology experiments (Fig. 7E2).

Fluorescence-guided patch-clamp recordings of $\mathrm{GFP}^{+/-}$cells were performed in slices from the cFos-GFP transgenic rats (Fig. $7 F$; Whitaker et al., 2017). Where possible, we attempted to sample equal numbers of $\mathrm{GFP}^{+/-}$cells from each brain slice. In contrast to experiment 5 , the final extinction or cue-test session was halted after $90 \mathrm{~min}$ to maximize the likelihood of a cFos-GFP signal. The firing responses of $\mathrm{GFP}^{+}$and $\mathrm{GFP}^{-}$cells in the salineyoked and cocaine-SA groups after extinction differed (Fig. 7F; three-way ANOVA with repeated measures: treatment, $F_{(1,380)}=$ 1.02, $p=0.3140$; current, $F_{(1,380)}=58.80, p<0.0001$; $\mathrm{GFP}^{+/-}$, $F_{(1,380)}=0.99, p<0.3194$; interaction, $F_{(1,380)}=35.47, p<$ $0.0001)$. In particular, changes in the current amplitude varied by both treatment (saline-yoked or cocaine-SA) and GFP expression (Fig. $7 F$; current $\times$ treatment, $F_{(1,380)}=32.85, p<0.0001$; current $\left.\times \mathrm{GFP}^{+/-}, F_{(1,380)}=70.37, p<0.0001\right)$. Visual inspection of only the saline-yoked treatments suggested that the number of action potentials increased with increasing current injection, without obvious differences between $\mathrm{GFP}^{+}$and $\mathrm{GFP}^{-}$cells (Fig. $7 F$ ). In contrast, with the cocaine-SA treatments, $\mathrm{GFP}^{+}$and $\mathrm{GFP}^{-}$cell responses to depolarizing current appeared noticeably different (Fig. $7 F$ ). Even in brain slices from the same cocaine-SA with extinction animal, $\mathrm{GFP}^{+}$cells from cocaine-SA with extinction rats showed on average a threefold to fourfold enhancement of firing relative to the $\mathrm{GFP}^{-}$cells in the same animals $(1 \mathrm{nA}$ step). The dot-plot summary for firing indicated that most cells (both $\mathrm{GFP}^{+}$and $\mathrm{GFP}^{-}$) in the saline-yoked group displayed SFA after extinction (Fig. $7 F$ ). By contrast, in the cocaine-SA group, most GFP ${ }^{+}$cells lacked SFA, whereas the $\mathrm{GFP}^{-}$cells in the same group were qualitatively similar to saline-yoked responses after extinction (Fig. $7 F$ ).

Following extinction, AHPs in $\mathrm{GFP}^{+/-}$cells in the salineyoked and cocaine-SA treatment groups also differed (two-way ANOVA: treatment, $F_{(1,51)}=11.18, p=0.0016 ; \mathrm{GFP}^{+/-}, F_{(1,51)}$ $=3.74, p=0.0588$; interaction, $\left.F_{(1,51)}=4.10, p=0.0483\right)$. A follow-up analysis showed that AHPs in $\mathrm{GFP}^{+}$cells from cocaine-SA rats were reduced relative to the saline-yoked rats (Fig. $7 F$; post hoc test: $t_{(51)}=3.88, p=0.0017$ ). In contrast, AHPs in $\mathrm{GFP}^{-}$cells in the saline-yoked and cocaine-SA groups were similar (Fig. $7 F$; post hoc test: $t_{(51)}=0.91, p=0.7975$ ). Comparing AHP responses within respective treatment groups, GFP ${ }^{+}$ and $\mathrm{GFP}^{-}$cells were equivalent for the saline-yoked groups, but differed for the cocaine-SA groups (Fig. 7F; post hoc saline-yoked group, $t_{(51)}=-0.06, p=0.7975$; cocaine-SA group, $t_{(51)}=2.99$, $p=0.0218$ ). These data indicate that in animals with a history of cocaine-SA treatment (but not saline-yoked treatment), the expression of $\mathrm{GFP}^{+}$overlaps with the persistent reduction in intrinsic inhibition after extinction training.

The effect of cocaine-predictive cues was similar to that observed above with extinction; however, $\mathrm{GFP}^{-}$cells were typically more difficult to find. After cue exposure, the firing responses of $\mathrm{GFP}^{+/-}$cells in the saline-yoked and cocaine-SA groups also differed (Fig. 7G; three-way ANOVA with repeated measures of treatment: $F_{(1,401)}=2.26, p=01331$; current: $F_{(1,401)}=80.80$, $p<0.0001$; GFP ${ }^{+/-}: F_{(1,401)}=3.06, p<0.0812$; interaction: $\left.F_{(1,401)}=114.14, p<0.0001\right)$. As above, changes in the current 
A

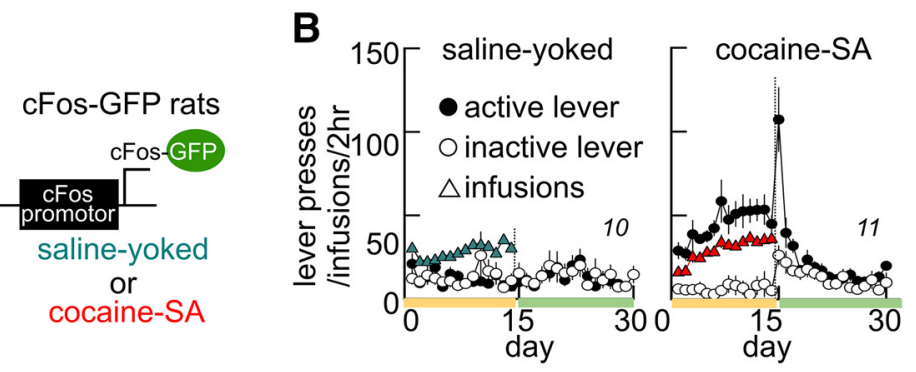

D1
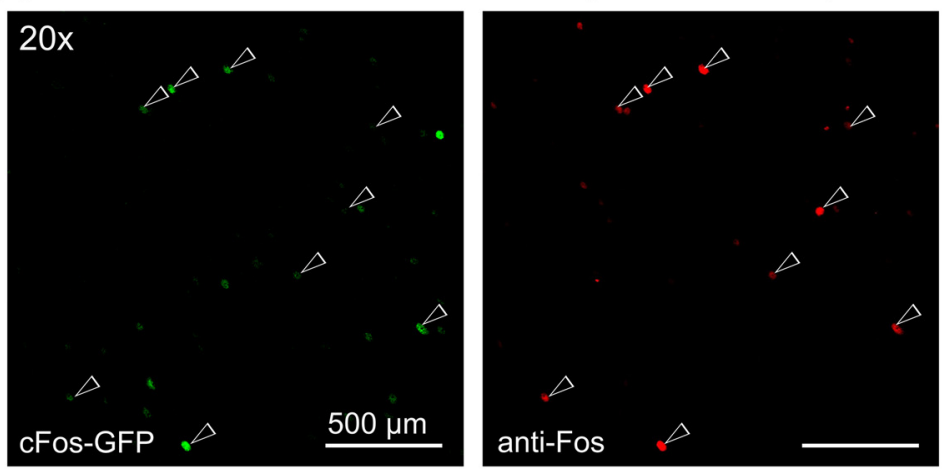

c

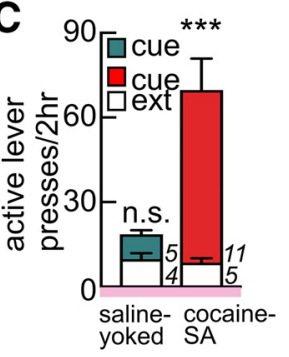

D2

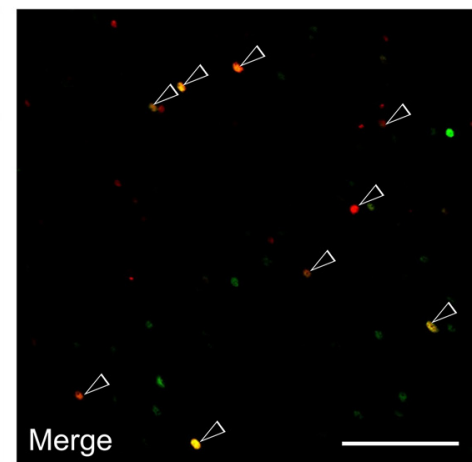

number of cells

co-localization

\begin{tabular}{lccccccc} 
& green & red & (yellow) & $F_{P}$ & $r$ & $M_{1}$ & $M_{2}$ \\
\hline saline-yoked & 3 & 2 & 2 & 0.97 & 0.99 & 0.83 & 1.18 \\
cocaine-SA & 17 & 26 & 10 & 0.92 & 0.99 & 1.01 & 0.96 \\
cocaine-SA + & 46 & 37 & 35 & 0.95 & 1.00 & 0.91 & 1.09 \\
End of Ext d1 & & & & & & &
\end{tabular}

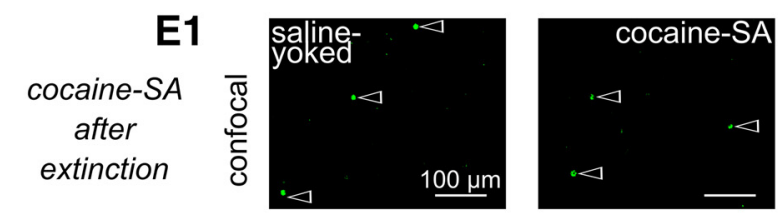

E2

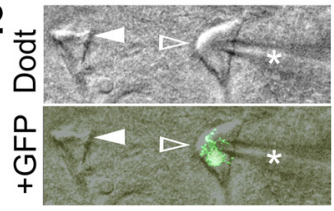

F

F 40
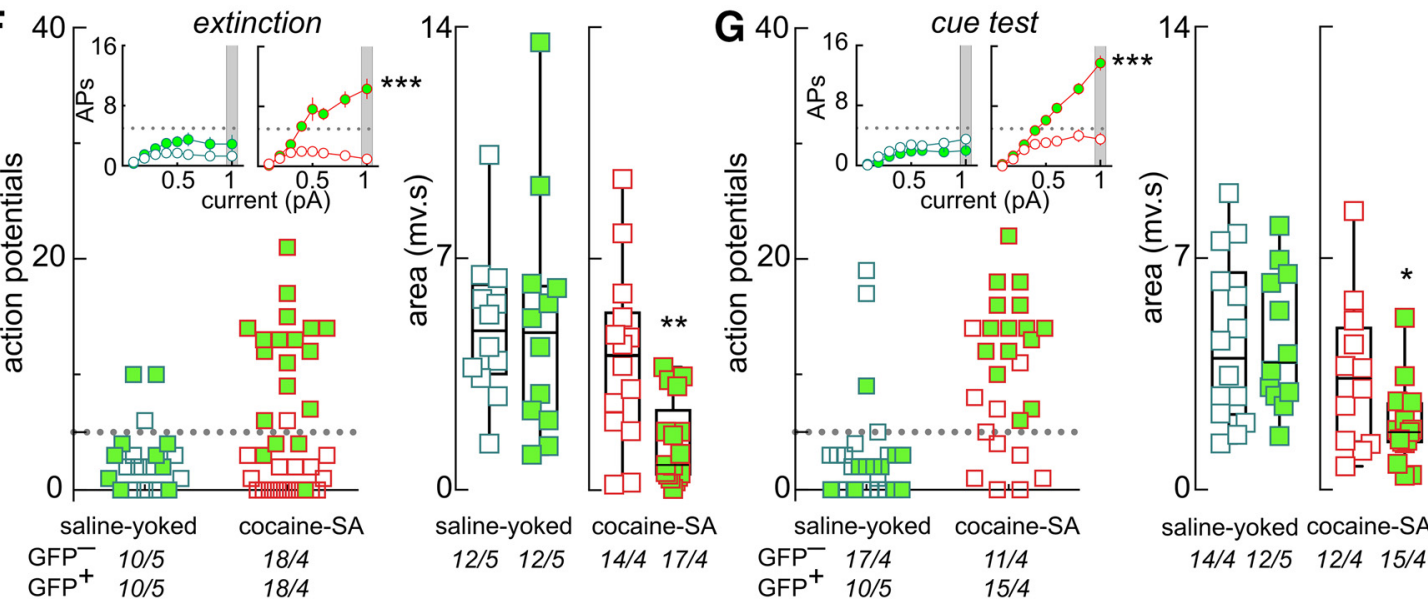

saline-yoked cocaine-SA $14 / 4 \quad 12 / 5 \quad 12 / 4 \quad 15 / 4$

Figure 7. Characterization of intrinsic inhibition in CFos-GFP ${ }^{+}$and CFos-GFP ${ }^{-}$cells in the PL-PFC after extinction and cued reinstatement of cocaine seeking. $A$, Schematic of the transgene containing a c-fos promoter that induces GFP in strongly activated Fos-expressing neurons, which can be sampled in electrophysiological slice preparations. $\boldsymbol{B}$, Lever-pressing behavior for Long-Evans rats providing the PL-PFC electrophysiology recordings and immunohistochemistry. Rats were presented with levers that resulted in the activation of a light and tone cue paired with the infusion of cocaine (cocaine-SA, right) or yoked passive infusion of saline (saline-yoked, left). The vertical dashed line on the time courses indicates the switch from SA to Ext. In Ext sessions, lever pressing had no consequence. C, Re-exposure to cues (without saline or rewards) significantly increased lever pressing in rats with a history of cocaine-SA (Sidak post hoc; ${ }^{* * *} p \leq 0.0001$, cue vs extinction). D1, Confocal photomicrographs showing colabeling (white arrows) of GFP (green) and Fos (red) using immunofluorescence histochemistry. Micrographs are from a c-Fos-GFP rat that underwent cocaine-SA and a single Ext training session before perfusion (day 15). D2, Table summarizing GFP/Fos colabeling in transgenic rats with different treatments: Rat 1, saline-yoked + 14 $\mathrm{d}$ EXT(killing on day 28); Rat 2-cocaine-SA (killing on day 14); Rat 3 cocaine-SA +1 d Ext (killing on day 15). A high degree of colocalization between fluorophores was evident from the Pearson's correlation coefficient ( $F_{p}$; summarizing the ratio of cells that colocalize) and Manders' overlap coefficient $(r$; showing the overlap between channels). E1, Confocal photomicrographs show similarly low levels of GFP-IR (open arrowheads) in the PFC of a saline-yoked (left) and cocaine-SA (right) rat immediately after the final Ext session (day 28). E2, Photomicrographs of pyramidal neurons in a living brain slice from a CFos-GFP rat killed after the final Ext session (day 28). Cells were visualized in the electrophysiology recording chamber by contrast (Figure legend continues.) 
amplitude varied by both treatment (saline-yoked or cocaine-SA) and GFP expression (Fig. $7 G$; current $\times$ treatment: $F_{(1,401)}=$ $140.37, p<0.0001$; current $\times \mathrm{GFP}^{+/-}: F_{(1,401)}=69.93, p<$ 0.0001 ). In the saline-yoked treatments, action potential firing in $\mathrm{GFP}^{+}$and GFP ${ }^{-}$cells increased in a similar fashion (Fig. $7 G$ ). In contrast, in cocaine-SA treatments, the response of $\mathrm{GFP}^{+}$and $\mathrm{GFP}^{-}$cells to depolarizing current was noticeably different, and all $\mathrm{GFP}^{+}$cells lacked SFA (Fig. 7F). In the cocaine-SA group, $\mathrm{GFP}^{+}$cells showed a fourfold greater number of action potentials than in the $\mathrm{GFP}^{-}$cells ( $1 \mathrm{nA}$ step). After cue exposure, AHPs in $\mathrm{GFP}^{+/-}$cells in the cocaine-SA and saline-yoked treatments differed as a function of treatment (Fig. 7G; two-way ANOVA: treatment, $F_{(1,49)}=10.00, p=0.0027 ; \mathrm{GFP}^{+/-}, F_{(1,49)}=1.73, p<$ 0.1944 ; interaction, $\left.F_{(1,49)}=1.96, p<0.1681\right)$. Data from the extinction and cued reinstatement experiments shown above indicate that the $\mathrm{SFA}^{-}$cells from rats with a history of cocaine-SA and conditioned cues also express cFos-GFP. In other studies, in behaviorally extinguished animals, $\mathrm{GFP}^{+}$neurons comprising ensemble networks display strong activation in response to drug context environments (Koya et al., 2009, 2012). The nature of the Fos-generating stimulus in our behaviorally extinguished cocaine-SA animals remains to be determined.

Collectively, the above studies demonstrate that the reduction of intrinsic inhibition in a subpopulation of PL-PFC neurons after repeated operant cocaine-SA coincides temporally with changes in both drug seeking and neuronal activation. In summary, these experiments indicate the following: (1) operant training for a drug (cocaine) or nondrug (sucrose) reinforcer is associated with neuromodification of two powerful types of intrinsic inhibition; (2) whereas the modification for the nondrug reinforcer resolves during extinction, it persists for the drug reinforcer cocaine in a subpopulation of cells throughout extinction and cued reinstatement of cocaine seeking; and (3) the persistent excitability is also associated with a Fos- $\mathrm{GFP}^{+}$signature. Whether the activation of Fos reflects a re-exposure to the same environment where the animal first learned to associate the light and tone cues with cocaine or, alternatively, reflects that competing activation of different ensembles (extinction vs cue) remains to be determined.

\section{Discussion}

In rats, we found that learning to self-administer a drug reinforcer (cocaine) reduced PL-PFC intrinsic inhibition (as measured by SFA and AHPs) mediated by Kv7 channels. This modification persisted in a subpopulation of PL-PFC neurons throughout extinction and was enhanced further by exposure to drug-predictive cues. Such modifications were absent after simi-

\footnotetext{
(Figure legend continued.) (Dodt) optics, and overlayed with pseudocolor fluorescence to show a GFP ${ }^{+}$(open arrowhead) and a GFP ${ }^{-}$(closed arrowhead) nucleus. Star indicates the recording electrode. All subjects were killed immediately following their final $90 \mathrm{~min}$ behavioral session. $\boldsymbol{F}, \mathbf{G}$, Comparison of responses from $\mathrm{GFP}^{+}$and GFP ${ }^{-}$cells from cocaine-SA-treated (red) and saline-yoked-treated (blue) rats following Ext $(\boldsymbol{F})$ or cue reinstatement $(\boldsymbol{G})$. Closed and open symbols denote responses in GFP ${ }^{+}$and GFP ${ }^{-}$cells, respectively. Measurements included average firing (inset, I- 0 curves), individual firing (scatter plots of responses at $1 \mathrm{nA}$ ), and AHPs (scatter plots). Where possible, equal numbers of $\mathrm{GFP}^{+} / \mathrm{GFP}^{-}$cells in animals were sampled. Note the elevated firing and reduced AHPs only in a subset of GFP ${ }^{+}$cells from cocaine-SA rats, but not from saline-yoked rats. Italicized numbers in $\boldsymbol{B}$ indicate the number of animals, whereas those in $\boldsymbol{C}, \boldsymbol{F}$, and $\boldsymbol{G}$ indicate the number of cells/animal. Tukey multiple comparison post-test: ${ }^{* * *} p \leq 0.0001$ (current $\times$ treatment and current $\times \mathrm{GFP}^{+/-}$) comparing I- 0 (insets) after extinction or cue; ${ }^{* *} p=0.0218$ comparing AHPs from $\mathrm{GFP}^{+}$and $\mathrm{GFP}^{-}$cells from the cocaine-SA group after extinction; ${ }^{*} p \leq 0.05$ effect of treatment comparing AHPs after cue.
}

lar treatments with a nondrug reinforcer (sucrose) or the same drug reinforcer (cocaine) administered passively under a yoked schedule. Cellular plasticity that is resistant to behavioral extinction and unusually robust is considered important for drugseeking behaviors. An existing prevailing theory is that drug seeking stems from repeated intense neuronal activity that causes downstream biochemical changes in signal transduction, and thereby alters the responsiveness of cortical neurons to neurotransmitters that encode and interpret cues. In line with this, we found that dopamine regulation of intrinsic inhibition was occluded only in this hyper-responsive neural subpopulation and coincided with the expression of the cFos-GFP transgene, suggesting prior robust dopamine transmission. Pharmacological stabilization of Kv7 channels with retigabine normalized SFA, potentiated $I_{\mathrm{Kv}}$, and reduced reinstatement behavior. By contrast, cells lacking this modification showed normal levels of $I_{\mathrm{Kv}}$ inhibition and insensitivity to retigabine, suggesting that some pharmacological specificity for the activated subpopulation of cells mediating drug seeking. As Western blot analysis showed no overall changes in channel protein expression levels, it appears that repeated cocaine-SA causes a functional desensitization of inhibitory Kv7 channels. Given the role of SFA in the synchronization of neuronal assemblies, this pathological shift away from intrinsic inhibition in this subpopulation of neurons may facilitate drug-seeking behavior.

\section{Role of intrinsic inhibition in cocaine self-administration and seeking}

In primate PFC, learning to acquire a nondrug reward results in the formation of task-relevant neural ensembles (Buschman et al., 2012). The flexible nature of ensembles to form and reform underlies cognitive flexibility (Sejnowski and Paulsen, 2006; Womelsdorf and Fries, 2007). Chronic drug use impairs cognitive flexibility, rendering addicts unable to shift away from behavioral patterns learned during drug taking (Briand et al., 2008; Kalivas and O'Brien, 2008; Porter et al., 2011; Schultz, 2011). SFA and AHPs are candidate cellular mechanisms that promote learning and memory by facilitating neuronal synchronization (Crook et al., 1998; Prescott and Sejnowski, 2008; Prescott et al., 2008; Sehgal et al., 2014). Transient reductions in SFA/AHP mechanisms by neuromodulators like dopamine accelerate the transition of LTD into LTP (Zaitsev and Anwyl, 2012). In other brain regions, reductions in intrinsic inhibition bias the recruitment of neuronal ensembles toward excitation and facilitate memory storage (Yiu et al., 2014) and possibly behavioral responses to drug-associated cues.

Reductions in intrinsic inhibition are learning specific (Moyer et al., 1996; Thompson et al., 1996). Because such reductions are normally transient and normalize shortly after behavioral learning, the underlying mechanisms are considered essential for memory consolidation (Moyer et al., 1996). The restabilization or recovery of inhibition is equally important then to acquire new learning and to extinguish a behavior (Kufahl et al., 2009; Pentkowski et al., 2012, 2014). Thus, persistent drug memories and craving could be associated with deficits in this process. In this regard, our finding that reinforcement learning for a drug reinforcer (cocaine) and a nondrug reinforcer (sucrose) differentially altered intrinsic inhibition is important. Drug and nondrug reinforcers differ in the degree to which they facilitate PFC dopamine release and form cue-reinforcement associations (Ciccocioppo et al., 2004; Tunstall and Kearns, 2014; Tunstall et al., 2014). Following repeated cocaine-SA, the combination of robust release of 
PFC dopamine and persistent unremitting reduction in intrinsic inhibition may bias cortical function toward future drug seeking.

\section{Select adaptations in a subpopulation of PL-PFC neurons}

Previous studies indicate that sparse ensembles of neurons can encode a "seek" rule learned by the repeated presentation of drug-predictive cues and that selective ablation or inactivation of these neurons reduces reinstatement for food and drug seeking (Bossert et al., 2011; Cruz et al., 2014; Warren et al., 2016; Whitaker et al., 2017) as well as incubation of drug craving (Fanous et al., 2012; Funk et al., 2016; Caprioli et al., 2017). These studies used cFos-LacZ transgenic rat strategies, whereby the LacZ signal serves as a proxy for the endogenous cFos gene product, and can also be targeted for selective inactivation by Duano2 (Cruz et al., 2013). The Fos gene product is a known neuronal marker of intense firing activity (Morgan and Curran, 1991) and is activated by cocaine self-administration and context or cue-induced reinstatement (for review, see Cruz et al., 2015). Fos expression requires robust elevations in calcium influx (McClung and Nestler, 2008) and is associated with downstream biochemical changes that regulate gene expression (Cruz et al., 2013).

Activity-induced increases in Fos are considered to represent the integration of neuronal activity driven by numerous synaptic alterations (Cifani et al., 2012; Koya et al., 2012; Whitaker et al., 2017; Ziminski et al., 2017, 2018). Using cFos-GFP transgenic rats, we observed that cocaine-SA training decreased intrinsic inhibition selectively in $\mathrm{cFos} / \mathrm{GFP}^{+}$neurons. Although the increased firing and increased Fos is logical, it contrasts with other reports showing reductions in excitatory synaptic strength (AMPAR/NMDAR current ratios) and glutamate release in cFos/ $\mathrm{GFP}^{+}$cells after stress reinstatement of food seeking (Cifani et al., 2012; Koya et al., 2012). In those instances, the disparity in the cFos and excitation relationship was explained to reflect indirect homeostatic counteradaptations. Differences in those studies and our results may reflect differing reinforcers, brain regions, or the use of drug-associated cues. Regardless, these studies and ours highlight the importance of studying functional changes, both synaptic and intrinsic, in behaviorally relevant neurons.

\section{The influence of dopamine}

Dopamine exerts a multifaceted role in learning (Hollerman and Schultz, 1998), network connectivity (Eytan et al., 2004), and neuronal synchronization (Puig et al., 2014), including a stabilizing influence on cellular activity within neural ensembles (O’Donnell, 2003; Puig and Miller, 2012; Miyawaki et al., 2014). The role of dopamine in drug reward processing appears to facilitate the encoding of reward prediction, imprinting incentive value to reinforcers (energizing approach behavior) and facilitating the learning of reward associations (conditioning) through its modulation of subcortical (including the nucleus accumbens) and cortical brain regions (Di Chiara, 1999; Schultz, 1999, 2002; Waelti et al., 2001; Redish, 2004; Steinberg et al., 2013). Cellular adaptations in dopaminergic signaling contribute to relapse to drug seeking (Hyman et al., 2006), in part by disrupting transmission in the prefrontal cortex (Anderson and Pierce, 2005; Dong et al., 2005; Huang et al., 2007; Sidiropoulou et al., 2009; Buchta and Riegel, 2015). In tissue from rats with a history of repeated cocaine-SA training, we observed a decreased ability of dopamine to alter firing and $I_{\mathrm{Kv} 7}$ in a subpopulation of cells, which may reflect prior sensitization or overactivation in this neuronal population. Unexpectedly, the $\mathrm{SFA}^{+}$population of cells from both the saline-yoked and the cocaine-SA treatments showed normal responses to dopamine, indicating some neuro- nal selectivity in the modification of intrinsic inhibition. The reason for this selectivity is unclear but may reflect differences in dopamine receptor expression. Chronic exposure to cocaine causes rapid, robust, and persistent increases in D1 receptormediated signaling that result in a prominent upregulation of Fos (Henry and White, 1995; McClung and Nestler, 2003). Functional D1 receptors are required for Fos induction by cocaine (Drago et al., 1996; Moratalla et al., 1996; Zhang et al., 2002, 2004), and cocaine-induced behaviors are greatly reduced in transgenic mice with inactivated Fos in D1 receptor-expressing cells throughout the brain (Zhang et al., 2006). In SFA ${ }^{-}$cells, we observed both occluded dopamine responses and a strong association with the cFos-GFP transgene (even under extinction-like conditions). Perhaps prior robust overactivation or sensitization of dopamine signaling functionally reduces intrinsic inhibition and further modulation by dopamine in these neurons.

\section{Kv7 ion channels}

Why Kv7 channel currents are reduced following cocaine-SA is unclear. Cocaine exposure is known to elevate levels of intracellular calcium, which reportedly can initiate a well described calmodulin-sensitive suppression of the Kv7 ion channel activity, resulting in hyperexcitability (Kirkwood et al., 1991; Selyanko and Brown, 1996; Cruzblanca et al., 1998; Gamper and Shapiro, 2003; Gamper et al., 2003). Other possible mechanisms regulating the channel will also need to be examined, including elevated cAMP and protein kinase A activity (Dong et al., 2005; Nasif et al., 2005; Ford et al., 2009) and/or reduced levels of PtdIns(4,5)P2 (Park et al., 2001; Zhang and Linden, 2003; Li et al., 2005). The adaptations outlined above all likely contribute to increased cueinduced drug-seeking behavior long after the cessation of drug use. Nevertheless, our results demonstrate a functional role for Kv7 channel-mediated inhibition in a behaviorally relevant subpopulation of PL-PFC neurons important for cue-induced reinstatement of drug seeking. Future studies combining pharmacological treatments like retigabine with newer strategies for time-sensitive labeling of behaviorally relevant neurons using cFos-TetTag in transgenic mice (Reijmers et al., 2007) may further refine precisely when these adaptations disrupt Kv7 channel function and how this contributes to cue-induced cocaine seeking.

\section{References}

Aiken SP, Lampe BJ, Murphy PA, Brown BS (1995) Reduction of spike frequency adaptation and blockade of $\mathrm{M}$-current in rat CA1 pyramidal neurones by linopirdine (DuP 996), a neurotransmitter release enhancer. Br J Pharmacol 115:1163-1168. CrossRef Medline

Anderson SM, Pierce RC (2005) Cocaine-induced alterations in dopamine receptor signaling: implications for reinforcement and reinstatement. Pharmacol Ther 106:389-403. CrossRef Medline

Battefeld A, Tran BT, Gavrilis J, Cooper EC, Kole MH (2014) Heteromeric Kv7.2/7.3 channels differentially regulate action potential initiation and conduction in neocortical myelinated axons. J Neurosci 34:3719-3732. CrossRef Medline

Benda J, Longtin A, Maler L (2005) Spike-frequency adaptation separates transient communication signals from background oscillations. J Neurosci 25:2312-2321. CrossRef Medline

Bobadilla AC, Heinsbroek JA, Gipson CD, Griffin WC, Fowler CD, Kenny PJ, Kalivas PW (2017) Corticostriatal plasticity, neuronal ensembles, and regulation of drug-seeking behavior. Prog Brain Res 235:93-112. CrossRef Medline

Bossert JM, Stern AL, Theberge FR, Cifani C, Koya E, Hope BT, Shaham Y (2011) Ventral medial prefrontal cortex neuronal ensembles mediate context-induced relapse to heroin. Nat Neurosci 14:420-422. CrossRef Medline

Bossert JM, Marchant NJ, Calu DJ, Shaham Y (2013) The reinstatement 
model of drug relapse: recent neurobiological findings, emerging research topics, and translational research. Psychopharmacology 229:453-476. CrossRef Medline

Briand LA, Flagel SB, Garcia-Fuster MJ, Watson SJ, Akil H, Sarter M, Robinson TE (2008) Persistent alterations in cognitive function and prefrontal dopamine D2 receptors following extended, but not limited, access to self-administered cocaine. Neuropsychopharmacology 33:2969-2980. CrossRef Medline

Brown DA, Passmore GM (2009) Neural KCNQ (Kv7) channels. Br J Pharmacol 156:1185-1195. CrossRef Medline

Buchta WC, Riegel AC (2015) Chronic cocaine disrupts mesocortical learning mechanisms. Brain Res 1628:88-103. CrossRef Medline

Buchta WC, Mahler SV, Harlan B, Aston-Jones GS, Riegel AC (2017) Dopamine terminals from the ventral tegmental area gate intrinsic inhibition in the prefrontal cortex. Physiol Rep 5:e13198. CrossRef Medline

Buschman TJ, Denovellis EL, Diogo C, Bullock D, Miller EK (2012) Synchronous oscillatory neural ensembles for rules in the prefrontal cortex. Neuron 76:838-846. CrossRef Medline

Caprioli D, Venniro M, Zhang M, Bossert JM, Warren BL, Hope BT, Shaham Y (2017) Role of dorsomedial striatum neuronal ensembles in incubation of methamphetamine craving after voluntary abstinence. J Neurosci 37:1014-1027. CrossRef Medline

Ceci A, Brambilla A, Duranti P, Grauert M, Grippa N, Borsini F (1999) Effect of antipsychotic drugs and selective dopaminergic antagonists on dopamine-induced facilitatory activity in prelimbic cortical pyramidal neurons. an in vitro study. Neuroscience 93:107-115. CrossRef Medline

Ciccocioppo R, Martin-Fardon R, Weiss F (2004) Stimuli associated with a single cocaine experience elicit long-lasting cocaine-seeking. Nat Neurosci 7:495-496. CrossRef Medline

Cifani C, Koya E, Navarre BM, Calu DJ, Baumann MH, Marchant NJ, Liu QR, Khuc T, Pickel J, Lupica CR, Shaham Y, Hope BT (2012) Medial prefrontal cortex neuronal activation and synaptic alterations after stressinduced reinstatement of palatable food seeking: a study using c-fos-GFP transgenic female rats. J Neurosci 32:8480-8490. CrossRef Medline

Coulter DA, Lo Turco JJ, Kubota M, Disterhoft JF, Moore JW, Alkon DL (1989) Classical conditioning reduces amplitude and duration of calcium-dependent afterhyperpolarization in rabbit hippocampal pyramidal cells. J Neurophysiol 61:971-981. CrossRef Medline

Crook SM, Ermentrout GB, Bower JM (1998) Spike frequency adaptation affects the synchronization properties of networks of cortical oscillations. Neural Comput 10:837-854. CrossRef Medline

Cruz FC, Koya E, Guez-Barber DH, Bossert JM, Lupica CR, Shaham Y, Hope BT (2013) New technologies for examining the role of neuronal ensembles in drug addiction and fear. Nat Rev Neurosci 14:743-754. CrossRef Medline

Cruz FC, Babin KR, Leao RM, Goldart EM, Bossert JM, Shaham Y, Hope BT (2014) Role of nucleus accumbens shell neuronal ensembles in contextinduced reinstatement of cocaine-seeking. J Neurosci 34:7437-7446. CrossRef Medline

Cruz FC, Javier Rubio F, Hope BT (2015) Using c-fos to study neuronal ensembles in corticostriatal circuitry of addiction. Brain Res 1628:157173. CrossRef Medline

Cruzblanca H, Koh DS, Hille B (1998) Bradykinin inhibits M current via phospholipase $\mathrm{C}$ and $\mathrm{Ca} 2+$ release from IP3-sensitive $\mathrm{Ca} 2+$ stores in rat sympathetic neurons. Proc Natl Acad Sci U S A 95:7151-7156. CrossRef Medline

Delmas P, Brown DA (2005) Pathways modulating neural KCNQ/M (Kv7) potassium channels. Nat Rev Neurosci 6:850-862. CrossRef Medline

Di Chiara G (1999) Drug addiction as dopamine-dependent associative learning disorder. Eur J Pharmacol 375:13-30. CrossRef Medline

Dong Y, Nasif FJ, Tsui JJ, Ju WY, Cooper DC, Hu XT, Malenka RC, White FJ (2005) Cocaine-induced plasticity of intrinsic membrane properties in prefrontal cortex pyramidal neurons: adaptations in potassium currents. J Neurosci 25:936-940. CrossRef Medline

Drago J, Gerfen CR, Westphal H, Steiner H (1996) D1 dopamine receptordeficient mouse: cocaine-induced regulation of immediate-early gene and substance P expression in the striatum. Neuroscience 74:813-823. CrossRef Medline

Epstein DH, Preston KL, Stewart J, Shaham Y (2006) Toward a model of drug relapse: an assessment of the validity of the reinstatement procedure. Psychopharmacology 189:1-16. CrossRef Medline

Euston DR, Gruber AJ, McNaughton BL (2012) The role of medial prefron- tal cortex in memory and decision making. Neuron 76:1057-1070. CrossRef Medline

Eytan D, Minerbi A, Ziv N, Marom S (2004) Dopamine-induced dispersion of correlations between action potentials in networks of cortical neurons. J Neurophysiol 92:1817-1824. CrossRef Medline

Faber ES, Callister RJ, Sah P (2001) Morphological and electrophysiological properties of principal neurons in the rat lateral amygdala in vitro. J Neurophysiol 85:714-723. CrossRef Medline

Fanous S, Goldart EM, Theberge FR, Bossert JM, Shaham Y, Hope BT (2012) Role of orbitofrontal cortex neuronal ensembles in the expression of incubation of heroin craving. J Neurosci 32:11600-11609. CrossRef Medline

Ford KA, Wolf ME, Hu XT (2009) Plasticity of L-type Ca2 + channels after cocaine withdrawal. Synapse 63:690-697. CrossRef Medline

Funk D, Coen K, Tamadon S, Hope BT, Shaham Y, Lê AD (2016) Role of central amygdala neuronal ensembles in incubation of nicotine craving. J Neurosci 36:8612-8623. CrossRef Medline

Gamper N, Shapiro MS (2003) Calmodulin mediates Ca2+-dependent modulation of M-type K+ channels. J Gen Physiol 122:17-31. CrossRef Medline

Gamper N, Stockand JD, Shapiro MS (2003) Subunit-specific modulation of KCNQ potassium channels by src tyrosine kinase. J Neurosci 23:84-95. Medline

Gipson CD, Kupchik YM, Shen H, Reissner KJ, Thomas CA, Kalivas PW (2013) Relapse induced by cues predicting cocaine depends on rapid, transient synaptic potentiation. Neuron 77:867-872. CrossRef Medline

Gipson CD, Kupchik YM, Kalivas PW (2014) Rapid, transient synaptic plasticity in addiction. Neuropharmacology 76:276-286. CrossRef Medline

Gorelova N, Seamans JK, Yang CR (2002) Mechanisms of dopamine activation of fast-spiking interneurons that exert inhibition in rat prefrontal cortex. J Neurophysiol 88:3150-3166. CrossRef Medline

Graybiel AM (2008) Habits, rituals, and the evaluative brain. Annu Rev Neurosci 31:359-387. CrossRef Medline

Gu N, Vervaeke K, Hu H, Storm JF (2005) Kv7/KCNQ/M and HCN/h, but not KCa2/SK channels, contribute to the somatic medium afterhyperpolarization and excitability control in CA1 hippocampal pyramidal cells. J Physiol 566:689-715. CrossRef Medline

Gulledge AT, Jaffe DB (1998) Dopamine decreases the excitability of layer V pyramidal cells in the rat prefrontal cortex. J Neurosci 18:9139-9151. CrossRef Medline

Henry DJ, White FJ (1995) The persistence of behavioral sensitization to cocaine parallels enhanced inhibition of nucleus accumbens neurons. J Neurosci 15:6287-6299. CrossRef Medline

Henze DA, González-Burgos GR, Urban NN, Lewis DA, Barrionuevo G (2000) Dopamine increases excitability of pyramidal neurons in primate prefrontal cortex. J Neurophysiol 84:2799-2809. CrossRef Medline

Herrera DG, Robertson HA (1996) Activation of in the brain. Prog Neurobiol 50:83-107. CrossRef Medline

Hollerman JR, Schultz W (1998) Dopamine neurons report an error in the temporal prediction of reward during learning. Nat Neurosci 1:304-309. CrossRef Medline

Huang CC, Yang PC, Lin HJ, Hsu KS (2007) Repeated cocaine administration impairs group II metabotropic glutamate receptor-mediated longterm depression in rat medial prefrontal cortex. J Neurosci 27:2958-2968. CrossRef Medline

Huang H, Trussell LO (2011) KCNQ5 channels control resting properties and release probability of a synapse. Nat Neurosci 14:840-847. CrossRef Medline

Hyman SE, Malenka RC, Nestler EJ (2006) Neural mechanisms of addiction: the role of reward-related learning and memory. Annu Rev Neurosci 29:565-598. CrossRef Medline

Johnston CA, Watts VJ (2003) Sensitization of adenylate cyclase: a general mechanism of neuroadaptation to persistent activation of Galpha(i/o)coupled receptors? Life Sci 73:2913-2925. CrossRef Medline

Kalivas PW, McFarland K (2003) Brain circuitry and the reinstatement of cocaine-seeking behavior. Psychopharmacology 168:44-56. CrossRef Medline

Kalivas PW, O’Brien C (2008) Drug addiction as a pathology of staged neuroplasticity. Neuropsychopharmacology 33:166-180. CrossRef Medline

Kirkwood A, Simmons MA, Mather RJ, Lisman J (1991) Muscarinic suppression of the $\mathrm{M}$-current is mediated by a rise in internal Ca2+ concentration. Neuron 6:1009-1014. CrossRef Medline 
Koya E, Golden SA, Harvey BK, Guez-Barber DH, Berkow A, Simmons DE, Bossert JM, Nair SG, Uejima JL, Marin MT, Mitchell TB, Farquhar D, Ghosh SC, Mattson BJ, Hope BT (2009) Targeted disruption of cocaineactivated nucleus accumbens neurons prevents context-specific sensitization. Nat Neurosci 12:1069-1073. CrossRef Medline

Koya E, Cruz FC, Ator R, Golden SA, Hoffman AF, Lupica CR, Hope BT (2012) Silent synapses in selectively activated nucleus accumbens neurons following cocaine sensitization. Nat Neurosci 15:1556-1562. CrossRef Medline

Kufahl PR, Zavala AR, Singh A, Thiel KJ, Dickey ED, Joyce JN, Neisewander JL (2009) c-fos expression associated with reinstatement of cocaineseeking behavior by response-contingent conditioned cues. Synapse 63: 823-835. CrossRef Medline

Lancaster B, Nicoll RA (1987) Properties of two calcium-activated hyperpolarizations in rat hippocampal neurones. J Physiol 389:187-203. CrossRef Medline

Lawrence JJ, Saraga F, Churchill JF, Statland JM, Travis KE, Skinner FK, McBain CJ (2006) Somatodendritic Kv7/KCNQ/M channels control interspike interval in hippocampal interneurons. J Neurosci 26:1232512338. CrossRef Medline

Lerman DC, Iwata BA (1995) Prevalence of the extinction burst and its attenuation during treatment. J Appl Behav Anal 28:93-94. CrossRef Medline

Li Y, Gamper N, Hilgemann DW, Shapiro MS (2005) Regulation of Kv7 (KCNQ) $\mathrm{K}^{+}$channel open probability by phosphatidylinositol 4,5bisphosphate. J Neurosci 25:9825-9835. CrossRef Medline

Madison DV, Nicoll RA (1982) Noradrenaline blocks accommodation of pyramidal cell discharge in the hippocampus. Nature 299:636-638. CrossRef Medline

Madison DV, Nicoll RA (1984) Control of the repetitive discharge of rat CA 1 pyramidal neurones in vitro. J Physiol 354:319-331. CrossRef Medline

Madison DV, Nicoll RA (1986) Actions of noradrenaline recorded intracellularly in rat hippocampal CA1 pyramidal neurones, in vitro. J Physiol 372:221-244. CrossRef Medline

Malenka RC, Nicoll RA (1986) Dopamine decreases the calcium-activated afterhyperpolarization in hippocampal CA1 pyramidal cells. Brain Res 379:210-215. CrossRef Medline

Matsumoto M, Hikosaka O (2009) Two types of dopamine neuron distinctly convey positive and negative motivational signals. Nature 459: 837-841. CrossRef Medline

McClung CA, Nestler EJ (2003) Regulation of gene expression and cocaine reward by CREB and DeltaFosB. Nat Neurosci 6:1208-1215. CrossRef Medline

McClung CA, Nestler EJ (2008) Neuroplasticity mediated by altered gene expression. Neuropsychopharmacology 33:3-17. CrossRef Medline

McGlinchey EM, James MH, Mahler SV, Pantazis C, Aston-Jones G (2016) Prelimbic to accumbens core pathway is recruited in a dopaminedependent manner to drive cued reinstatement of cocaine seeking. J Neurosci 36:8700-8711. CrossRef Medline

McKay BM, Matthews EA, Oliveira FA, Disterhoft JF (2009) Intrinsic neuronal excitability is reversibly altered by a single experience in fear conditioning. J Neurophysiol 102:2763-2770. CrossRef Medline

McLaughlin J, See RE (2003) Selective inactivation of the dorsomedial prefrontal cortex and the basolateral amygdala attenuates conditioned-cued reinstatement of extinguished cocaine-seeking behavior in rats. Psychopharmacology 168:57-65. CrossRef Medline

Miyawaki T, Norimoto H, Ishikawa T, Watanabe Y, Matsuki N, Ikegaya Y (2014) Dopamine receptor activation reorganizes neuronal ensembles during hippocampal sharp waves in vitro. PLoS One 9:e104438. CrossRef Medline

Moratalla R, Xu M, Tonegawa S, Graybiel AM (1996) Cellular responses to psychomotor stimulant and neuroleptic drugs are abnormal in mice lacking the D1 dopamine receptor. Proc Natl Acad Sci U S A 93:14928-14933. CrossRef Medline

Morgan JI, Curran T (1988) Calcium as a modulator of the immediate-early gene cascade in neurons. Cell Calcium 9:303-311. CrossRef Medline

Morgan JI, Curran T (1991) Proto-oncogene transcription factors and epilepsy. Trends Pharmacol Sci 12:343-349. CrossRef Medline

Morgan JI, Cohen DR, Hempstead JL, Curran T (1987) Mapping patterns of c-fos expression in the central nervous system after seizure. Science 237: 192-197. CrossRef Medline

Moyer JR Jr, Thompson LT, Disterhoft JF (1996) Trace eyeblink condition- ing increases CA1 excitability in a transient and learning-specific manner. J Neurosci 16:5536-5546. Medline

Moyer JR Jr, Power JM, Thompson LT, Disterhoft JF (2000) Increased excitability of aged rabbit CA1 neurons after trace eyeblink conditioning. J Neurosci 20:5476-5482. Medline

Nasif FJ, Hu XT, White FJ (2005) Repeated cocaine administration increases voltage-sensitive calcium currents in response to membrane depolarization in medial prefrontal cortex pyramidal neurons. J Neurosci 25:3674-3679. CrossRef Medline

O’Donnell P (2003) Dopamine gating of forebrain neural ensembles. Eur J Neurosci 17:429-435. CrossRef Medline

Oh MM, Disterhoft JF (2015) Increased excitability of both principal neurons and interneurons during associative learning. Neuroscientist 21: 372-384. CrossRef Medline

Park SJ, Itoh T, Takenawa T (2001) Phosphatidylinositol 4-phosphate 5-kinase type I is regulated through phosphorylation response by extracellular stimuli. J Biol Chem 276:4781-4787. CrossRef Medline

Pentkowski NS, Cheung TH, Toy WA, Adams MD, Neumaier JF, Neisewander JL (2012) Protracted withdrawal from cocaine self-administration flips the switch on 5-HT1B receptor modulation of cocaine abuse-related behaviors. Biol Psychiatry 72:396-404. CrossRef Medline

Pentkowski NS, Harder BG, Brunwasser SJ, Bastle RM, Peartree NA, Yanamandra K, Adams MD, Der-Ghazarian T, Neisewander JL (2014) Pharmacological evidence for an abstinence-induced switch in 5-HT1B receptor modulation of cocaine self-administration and cocaine-seeking behavior. ACS Chem Neurosci 5:168-176. CrossRef Medline

Peron SP, Gabbiani F (2009) Role of spike-frequency adaptation in shaping neuronal response to dynamic stimuli. Biol Cybern 100:505-520. CrossRef Medline

Pinto L, Dan Y (2015) Cell-type-specific activity in prefrontal cortex during goal-directed behavior. Neuron 87:437-450. CrossRef Medline

Porter JN, Olsen AS, Gurnsey K, Dugan BP, Jedema HP, Bradberry CW (2011) Chronic cocaine self-administration in rhesus monkeys: impact on associative learning, cognitive control, and working memory. J Neurosci 31:4926-4934. CrossRef Medline

Prescott SA, Sejnowski TJ (2008) Spike-rate coding and spike-time coding are affected oppositely by different adaptation mechanisms. J Neurosci 28:13649-13661. CrossRef Medline

Prescott SA, Ratté S, De Koninck Y, Sejnowski TJ (2008) Pyramidal neurons switch from integrators in vitro to resonators under in vivo-like conditions. J Neurophysiol 100:3030-3042. CrossRef Medline

Puig MV, Miller EK (2012) The role of prefrontal dopamine D1 receptors in the neural mechanisms of associative learning. Neuron 74:874-886. CrossRef Medline

Puig MV, Antzoulatos EG, Miller EK (2014) Prefrontal dopamine in associative learning and memory. Neuroscience 282:217-229. CrossRef Medline

Redish AD (2004) Addiction as a computational process gone awry. Science 306:1944-1947. CrossRef Medline

Reijmers LG, Perkins BL, Matsuo N, Mayford M (2007) Localization of a stable neural correlate of associative memory. Science 317:1230-1233. CrossRef Medline

Riegel AC, Williams JT (2008) CRF facilitates calcium release from intracellular stores in midbrain dopamine neurons. Neuron 57:559-570. CrossRef Medline

Rosenkranz JA, Grace AA (2002) Cellular mechanisms of infralimbic and prelimbic prefrontal cortical inhibition and dopaminergic modulation of basolateral amygdala neurons in vivo. J Neurosci 22:324-337. Medline

Schultz W (1999) The reward signal of midbrain dopamine neurons. News Physiol Sci 14:249-255. Medline

Schultz W (2002) Getting formal with dopamine and reward. Neuron 36: 241-263. CrossRef Medline

Schultz W (2011) Potential vulnerabilities of neuronal reward, risk, and decision mechanisms to addictive drugs. Neuron 69:603-617. CrossRef Medline

See RE (2009) Dopamine D1 receptor antagonism in the prelimbic cortex blocks the reinstatement of heroin-seeking in an animal model of relapse. Int J Neuropsychopharmacol 12:431-436. CrossRef Medline

Sehgal M, Ehlers VL, Moyer JR Jr (2014) Learning enhances intrinsic excitability in a subset of lateral amygdala neurons. Learn Mem 21:161-170. CrossRef Medline 
Sejnowski TJ, Paulsen O (2006) Network oscillations: emerging computational principles. J Neurosci 26:1673-1676. CrossRef Medline

Selyanko AA, Brown DA (1996) Intracellular calcium directly inhibits potassium $\mathrm{M}$ channels in excised membrane patches from rat sympathetic neurons. Neuron 16:151-162. CrossRef Medline

Shaham Y, Shalev U, Lu L, de Wit H, Stewart J (2003) The reinstatement model of drug relapse: history, methodology and major findings. Psychopharmacology 168:3-20. CrossRef Medline

Shah MM, Javadzadeh-Tabatabaie M, Benton DC, Ganellin CR, Haylett DG (2006) Enhancement of hippocampal pyramidal cell excitability by the novel selective slow-afterhyperpolarization channel blocker 3-(triphenylmethylaminomethyl)pyridine (UCL2077). Mol Pharmacol 70:14941502. CrossRef Medline

Sidiropoulou K, Lu FM, Fowler MA, Xiao R, Phillips C, Ozkan ED, Zhu MX, White FJ, Cooper DC (2009) Dopamine modulates an mGluR5mediated depolarization underlying prefrontal persistent activity. Nat Neurosci 12:190-199. CrossRef Medline

Smith AC, Kupchik YM, Scofield MD, Gipson CD, Wiggins A, Thomas CA, Kalivas PW (2014) Synaptic plasticity mediating cocaine relapse requires matrix metalloproteinases. Nat Neurosci 17:1655-1657. CrossRef Medline

Song C, Ehlers VL, Moyer JR Jr (2015) Trace fear conditioning differentially modulates intrinsic excitability of medial prefrontal cortex-basolateral complex of amygdala projection neurons in infralimbic and prelimbic cortices. J Neurosci 35:13511-13524. CrossRef Medline

Spencer S, Garcia-Keller C, Roberts-Wolfe D, Heinsbroek JA, Mulvaney M, Sorrell A, Kalivas PW (2017) Cocaine use reverses striatal plasticity produced during cocaine seeking. Biol Psychiatry 81:616-624. CrossRef Medline

Stefanik MT, Kupchik YM, Kalivas PW (2016) Optogenetic inhibition of cortical afferents in the nucleus accumbens simultaneously prevents cueinduced transient synaptic potentiation and cocaine-seeking behavior. Brain structure and function 221:1681-1689. CrossRef Medline

Steinberg EE, Keiflin R, Boivin JR, Witten IB, Deisseroth K, Janak PH (2013) A causal link between prediction errors, dopamine neurons and learning. Nat Neurosci 16:966-973. CrossRef Medline

Steketee JD, Kalivas PW (2011) Drug wanting: behavioral sensitization and relapse to drug-seeking behavior. Pharmacol Rev 63:348-365. CrossRef Medline

Storm JF (1990) Potassium currents in hippocampal pyramidal cells. Prog Brain Res 83:161-187. CrossRef Medline

Taniguchi M, Carreira MB, Cooper YA, Bobadilla AC, Heinsbroek JA, Koike N, Larson EB, Balmuth EA, Hughes BW, Penrod RD, Kumar J, Smith LN, Guzman D, Takahashi JS, Kim TK, Kalivas PW, Self DW, Lin Y, Cowan CW (2017) HDAC5 and its target gene, Npas4, function in the nucleus accumbens to regulate cocaine-conditioned behaviors. Neuron 96:130144.e136. CrossRef Medline

Thompson LT, Moyer JR Jr, Disterhoft JF (1996) Transient changes in excitability of rabbit CA3 neurons with a time course appropriate to support memory consolidation. J Neurophysiol 76:1836-1849. CrossRef Medline

Tunstall BJ, Kearns DN (2014) Reinstatement in a cocaine versus food choice situation: reversal of preference between drug and non-drug rewards. Addict Biol 19:838-848. CrossRef Medline

Tunstall BJ, Kearns DN (2016) Cocaine can generate a stronger conditioned reinforcer than food despite being a weaker primary reinforcer. Addict Biol 21:282-293. CrossRef Medline

Tunstall BJ, Riley AL, Kearns DN (2014) Drug specificity in drug versus food choice in male rats. Exp Clin Psychopharmacol 22:364-372. CrossRef Medline

Venniro M, Caprioli D, Shaham Y (2016) Animal models of drug relapse and craving: from drug priming-induced reinstatement to incubation of craving after voluntary abstinence. Prog Brain Res 224:25-52. CrossRef Medline
Waelti P, Dickinson A, Schultz W (2001) Dopamine responses comply with basic assumptions of formal learning theory. Nature 412:43-48. CrossRef Medline

Wang HS, Pan Z, Shi W, Brown BS, Wymore RS, Cohen IS, Dixon JE, McKinnon D (1998) KCNQ2 and KCNQ3 potassium channel subunits: molecular correlates of the M-channel. Science 282:1890-1893. CrossRef Medline

Warren BL, Mendoza MP, Cruz FC, Leao RM, Caprioli D, Rubio FJ, Whitaker LR, McPherson KB, Bossert JM, Shaham Y, Hope BT (2016) Distinct fos-expressing neuronal ensembles in the ventromedial prefrontal cortex mediate food reward and extinction memories. J Neurosci 36:6691-6703. CrossRef Medline

Whitaker LR, Warren BL, Venniro M, Harte TC, McPherson KB, Beidel J, Bossert JM, Shaham Y, Bonci A, Hope BT (2017) Bidirectional modulation of intrinsic excitability in rat prelimbic cortex neuronal ensembles and non-ensembles after operant learning. J Neurosci 37:8845-8856. CrossRef Medline

Williams CL, Buchta WC, Riegel AC (2014) CRF-R2 and the heterosynaptic regulation of VTA glutamate during reinstatement of cocaine seeking. J Neurosci 34:10402-10414. CrossRef Medline

Williams MJ, Adinoff B (2008) The role of acetylcholine in cocaine addiction. Neuropsychopharmacology 33:1779-1797. CrossRef Medline

Womelsdorf T, Fries P (2007) The role of neuronal synchronization in selective attention. Curr Opin Neurobiol 17:154-160. CrossRef Medline

Yang CR, Seamans JK (1996) Dopamine D1 receptor actions in layers V-VI rat prefrontal cortex neurons in vitro: modulation of dendritic-somatic signal integration. J Neurosci 16:1922-1935. CrossRef Medline

Yiu AP, Mercaldo V, Yan C, Richards B, Rashid AJ, Hsiang HL, Pressey J, Mahadevan V, Tran MM, Kushner SA, Woodin MA, Frankland PW, Josselyn SA (2014) Neurons are recruited to a memory trace based on relative neuronal excitability immediately before training. Neuron 83: 722-735. CrossRef Medline

Zaitsev AV, Anwyl R (2012) Inhibition of the slow afterhyperpolarization restores the classical spike timing-dependent plasticity rule obeyed in layer 2/3 pyramidal cells of the prefrontal cortex. J Neurophysiol 107:205215. CrossRef Medline

Zhang D, Zhang L, Lou DW, Nakabeppu Y, Zhang J, Xu M (2002) The dopamine D1 receptor is a critical mediator for cocaine-induced gene expression. J Neurochem 82:1453-1464. CrossRef Medline

Zhang J, Zhang L, Jiao H, Zhang Q, Zhang D, Lou D, Katz JL, Xu M (2006) c-fos facilitates the acquisition and extinction of cocaine-induced persistent changes. J Neurosci 26:13287-13296. CrossRef Medline

Zhang L, Lou D, Jiao H, Zhang D, Wang X, Xia Y, Zhang J, Xu M (2004) Cocaine-induced intracellular signaling and gene expression are oppositely regulated by the dopamine D1 and D3 receptors. J Neurosci 24: 3344-3354. CrossRef Medline

Zhang W, Linden DJ (2003) The other side of the engram: experiencedriven changes in neuronal intrinsic excitability. Nat Rev Neurosci 4:885900. CrossRef Medline

Zheng P, Zhang XX, Bunney BS, Shi WX (1999) Opposite modulation of cortical N-methyl-D-aspartate receptor-mediated responses by low and high concentrations of dopamine. Neuroscience 91:527-535. CrossRef Medline

Ziminski JJ, Hessler S, Margetts-Smith G, Sieburg MC, Crombag HS, Koya E (2017) Changes in appetitive associative strength modulates nucleus accumbens, but not orbitofrontal cortex neuronal ensemble excitability. J Neurosci 37:3160-3170. CrossRef Medline

Ziminski JJ, Sieburg MC, Margetts-Smith G, Crombag HS, Koya E (2018) Regional differences in striatal neuronal ensemble excitability following cocaine and extinction memory retrieval in fos-GFP mice. Neuropsychopharmacology 43:718-727. Medline 